Salustiano Gabriel Neto

\title{
Estudo do tempo de trânsito colônico em pacientes com megacólon chagásico com constipação
}

Dissertação apresentada à Faculdade de Medicina da Universidade de São Paulo para obtenção do título de Mestre em Ciências.

Área de Concentração: Cirurgia do Aparelho Digestivo

Orientadora: Profa. Dra. Angelita Habr-Gama

São Paulo 2003 


\section{FICHA CATALOGRÁFICA}

Preparada pela Biblioteca da

Faculdade de Medicina da Universidade de São Paulo

Creprodução autorizada pelo autor

\section{Gabriel Neto, Salustiano}

Estudo do tempo de trânsito colônico em pacientes com megacólon chagásico com constipação / Salustiano Gabriel Neto. -- São Paulo, 2003.

Dissertação(mestrado)--Faculdade de Medicina da Universidade de São Paulo.

Departamento de Gastroenterologia.

Área de concentração: Cirurgia do Aparelho Digestivo.

Orientadora: Angelita Habr Gama.

Descritores: 1.DOENÇA DE CHAGAS/complicações 2.MEGACÓLON/ fisiopatologia 3.DOENÇAS FUNCIONAIS DO CÓLON/fisiopatologia 4.MOTILIDADE GASTROINTESTINAL 5.MEIOS DE CONTRASTE 6.TRÂNSITO GASTROINTESTINAL

USP/FM/SBD-403/03 
Esta Dissertação foi desenvolvida dentro do Mestrado Interinstitucional entre as Faculdades de Medicina da Universidade de São Paulo e Universidade Federal de Goiás.

Unidade promotora - FMUSP

Coordenadores:

Prof. Dr. Bruno Zilberstein

Prof. Dr. Joaquim José Gama-Rodrigues

Unidade receptora - FMUFG

Coordenador:

Prof. Dr. Heitor Rosa 
Dedicatória

Ao Prof. Dr. Olívio Louro Costa pelos ensinamentos cirúrgicos e estímulo à carreira de docente.

À Ana Carolina e Amanda, minhas filhas e à Andressa, minha esposa, pela paciência e compreensão.

Aos meus pais Vânia e Pedro, o começo de tudo. 


\section{AGRADECIMENTOS}

À Profa. Dra. Angelita Habr-Gama, pelas orientações que facilitaram o desenvolvimento deste trabalho. Sua empolgação à atividade cientifíca me contagiou.

Ao Prof. Alejandro Luquetti Ostermayer abnegado ao estudo da doença de Chagas, responsável pela sorologia dos doentes.

Ao Prof. Dr. Enio Chaves de Oliveira, quem com seu fascínio pela atividade científica, participou ativamente de todas as fases deste trabalho.

Ao Prof. Dr. Antônio Carlos Ximenes do Departamento de Imaginologia da Faculdade de Medicina da Universidade Federal de Goiás, que gentilmente ajudou na realização dos exames de radiologia.

Aos Prof. Dr. Custódio dos Reis e Souza, Prof. Adelino Araújo dos Santos, Prof. Vail Izidoro da Costa, Prof. José Hermes Gomes Costa, da Disciplina de Técnica Operatória da Faculdade de Medicina da Universidade Federal de Goiás, os quais me apoiaram e facilitaram minhas atividades de docência durante a realização deste trabalho.

Ao Prof. Dr. Joaquim José Gama-Rodrigues e Prof. Dr. Bruno Zilberstein, coordenadores do curso de Mestrado Interinstitucional pelo apoio, ajuda e estímulos constantes, sempre presentes apesar da distância.

Ao Prof. Dr. José Márcio Neves Jorge, nas considerações e sugestões ao trabalho.

Aos colegas do curso de Mestrado Interinstitucional, pelo espírito de grupo e, em especial, ao Dr. Leósarte Alves e Dr. Hélio Ponciano Trevenzol idealizadores do Minter. 
Ao Prof. Dr. Heitor Rosa coordenador da Faculdade de Medicina da Universidade Federal de Goiás para o Mestrado Interinstitucional.

Aos funcionários da Faculdade de Medicina da Universidade Federal de Goiás, Sr. Carlos Alberto Siqueira e Humberto Costa Filho que pacientemente ajudaram na confecção deste trabalho e as secretárias da Coordenação de Pesquisa e Pós-Graduação, Deusa José de Souza, Benedita Santiago, Patrícia Menezes dos Santos, Andréia Pereira dos Santos e a Bibliotecária Maria Raquel Gomes Silva pela presteza e solicitude para a realização deste trabalho.

Ao casal Marilda e José Guterres que ajudaram na bibliografia.

Às Sras. Myrtes Freire de Lima e Sandra Régia da Paixão Macedo da PósGraduação do Departamento de Gastroenterologia da Faculdade de Medicina da Universidade de São Paulo que não mediram esforços para que a distância não fosse problema na realização deste trabalho.

À Profa. Dra. Eleuse Machado de Britto Guimarães, grande incentivadora dos programas de Pós-Graduação na Faculdade de Medicina da Universidade Federal de Goiás.

Ao Prof. Gersino Monteiro Filho, pela análise estatística deste trabalho.

Aos Profs. Noé Silva Santos e José Manoel Binda, e aos Drs. Luiz Carlos Paier e João Alípio Barcelos Noé, responsáveis por eu ser médico cirurgião e que estão sempre presentes no meu dia-a-dia. 


\section{SUMÁRIO}

LISTA DE ABREVIATURAS E SÍMBOLOS

LISTA DE TABELAS

LISTA DE FIGURAS

RESUMO

SUMMARY

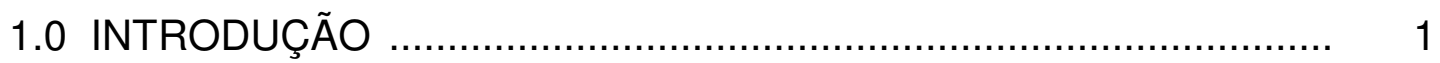

$1.1 \mathrm{~A}$ doença de Chagas .............................................................. 2

1.2 Forma digestiva da doença de Chagas ...................................... 4

1.3 Propedêutica da constipação …………......................................

1.4 Tempo de trânsito colônico ……………………………....... 8

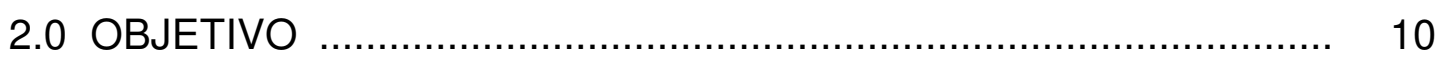

3.0 CASUÍSTICA E MÉTODOS ……............................................. 12

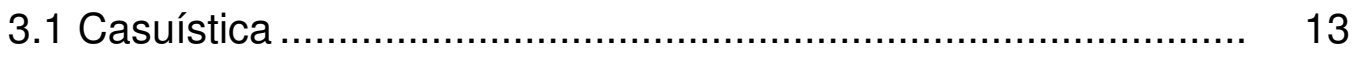

3.2 Preparo do doente ............................................................. 14

3.3 Tempo de trânsito colônico......................................................... 14

3.4 Análise estatística ................................................................. 16

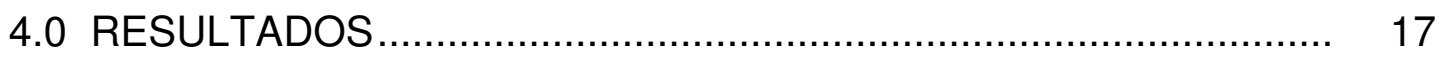

4.1 Pacientes com megacólon.................................................... 18

4.2 Pacientes do grupo controle .................................................. 19

4.3 Pacientes com megacólon: análise dos marcadores................. 20

4.4 Grupo controle: análise dos marcadores ................................ 25

4.5 Comparação entre os grupos controle e com megacólon .......... 26

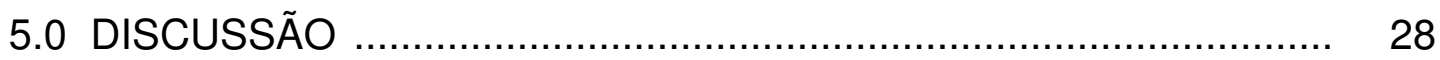

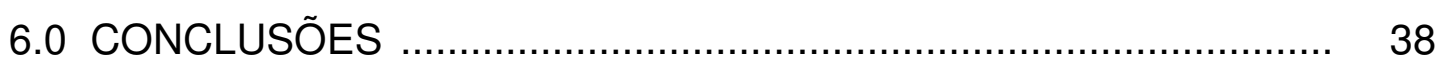

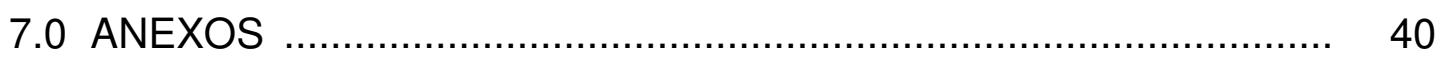

8.0 REFERÊNCIAS BIBLIOGRÁFICAS............................................ 49 


\section{LISTA DE ABREVIATURAS E SÍMBOLOS}

3CD número de marcadores no cólon direito no $3^{\circ}$ dia

3CE número de marcadores no cólon esquerdo no $3^{\circ}$ dia

3D número total de marcadores no $3^{\circ}$ dia

3RS número de marcadores no retossigmóide no $3^{\circ}$ dia

5CD número de marcadores no cólon direito no $5^{\circ}$ dia

5CE número de marcadores no cólon esquerdo no $5^{\circ}$ dia

5D número total de marcadores no $5^{\circ}$ dia

5RS número de marcadores no retossigmóide no $5^{\circ}$ dia

CD cólon direito

CE cólon esquerdo

DIAS dias de constipação

DIS data do início dos sintomas em anos

DP desvio padrão

e.g. por exemplo

et al e outros

EXP expelidos

ID identificação do paciente

MR megarreto

n número de casos

p nível descritivo

RS retossigmóide

TTC tempo de trânsito colônico 


\section{LISTA DE TABELAS}

TABELA 1. Idade dos pacientes ............................................................ 18

TABELA 2. Tempo do início dos sintomas (em anos)............................. 19

TABELA 3. Dias de constipação ............................................................ 19

TABELA 4. Distribuição dos pacientes quanto ao sexo e presença de megarreto.

TABELA 5. Grupo controle: médias e desvio padrão para a idade .......... 20

TABELA 6. Número médio de marcadores em todo o cólon no $3^{\circ}$ e $5^{\circ}$ dias

TABELA 7. Comparação do número de marcadores em cada segmento entre si no $3^{\circ}$ e $5^{\circ}$ dias nos doentes com megacólon.....

TABELA 8. Médias e desvio padrão do número de marcadores por segmento colônico.

TABELA 9. Médias e desvio padrão do número de marcadores por segmento colônico

TABELA 10. Análise estatística comparando o número de marcadores no $3^{\circ}$ e $5^{\circ}$ dias por segmento colônico

TABELA 11. Análise estatística das variáveis idade, sexo, início dos sintomas, dias de constipação e presença de megarreto em relação ao número de marcadores retidos por segmento colônico nos doentes com megacólon no $3^{\circ}$ e $5^{\circ}$ dias

TABELA 12. Grupo controle: médias e desvio padrão do número de marcadores por segmento no $3^{\circ}$ e $5^{\circ}$ dias

TABELA 13. Grupo controle: médias e desvio padrão do número total de marcadores no $3^{\circ}$ e $5^{\circ}$ dias.

TABELA 14. Análise estatística comparando o número de marcadores nos doentes com megacólon e grupo controle no $3^{\circ}$ e $5^{\circ}$ dias nos diferentes segmentos do cólon. 


\section{LISTA DE FIGURAS}

Figura 1. Prevalência da doença de Chagas ................................. 3

Figura 2. A - Enema opaco de paciente com megacólon; B - Megarreto; C - Reto normal .................................... 15

Figura 3. Marcador radiopaco da marca Sitzmarks contendo 24 marcadores em forma de anéis por cápsula (Fort Worth, EEUU)

Figura 4. Tempo de trânsito colônico no $3^{\circ}$ e $5^{\circ}$ dias do exame As linhas mostram a divisão dos cólons: direito (CD), esquerdo (CE) e retossigmóide (RS)

Figura 5. Número de marcadores por segmento colônico em pacientes do sexo feminino com megarreto

Figura 6. Número de marcadores por segmento colônico em pacientes do sexo feminino sem megarreto

Figura 7. Número de marcadores por segmento colônico em pacientes do sexo masculino com megarreto

Figura 8. Número de marcadores por segmento colônico em pacientes do sexo masculino sem megarreto. 


\section{RESUMO}


GABRIEL NETO, S. Estudo do tempo de trânsito colônico em pacientes com megacólon chagásico com constipação. São Paulo, 2003. 56p. Dissertação (Mestrado) - Faculdade de Medicina, Universidade de São Paulo.

O megacólon chagásico pode acometer até $10 \%$ dos pacientes na fase crônica da doença e o principal sintoma é a constipação intestinal que pode variar de dias a meses. Vários aspectos da fisiopatologia do megacólon não são bem compreendidos. $O$ objetivo deste trabalho foi avaliar o tempo de trânsito colônico com marcadores radiopacos em portadores de megacólon chagásico com constipação intestinal crônica acima de oito dias. Foram estudados 64 pacientes ( 36 mulheres e 28 homens), idade variando de 32 a 76 anos, com história clínica de constipação intestinal crônica, diagnóstico radiológico por enema opaco de megacólon e com provas sorológicas positivas para doença de Chagas. Foi considerado como megacólon quando o diâmetro do cólon era maior ou igual $6,5 \mathrm{~cm}$. Para avaliar o tempo de trânsito colônico, cada paciente ingeriu uma cápsula contendo 24 marcadores em forma de anéis radiopacos (Sitzmarks, Consil Pharmaceutics, Fort Worth, EEUU), e realizadas radiografias simples de abdome (ortostase) após três e cinco dias. Um grupo de 20 pacientes, sem constipação e com sorologia negativa para doença de Chagas, foi avaliado pela mesma metodologia e considerado como controle. A interpretação da localização e contagem dos marcadores foi realizada dividindo-se o intestino grosso nos segmentos: cólon direito, cólon esquerdo e retossigmóide. Empregou-se o teste de Kolmogorov-Smirnov para comparação do número de marcadores colônicos entre si e no $3^{\circ}$ e $5^{\circ}$ dias. O número de marcadores em cada grupo, em períodos distintos, foi avaliado com o teste de Wilcoxon. O coeficiente de correlação de Pearson foi utilizado para se avaliar a influência dos fatores externos (sexo, idade, tempo do início dos sintomas em anos, dias de constipação e presença de megarreto). O tempo de início dos sintomas variou de um a 33 anos e a duração da constipação, em dias, variou de oito a 90 dias. O megarreto ocorreu em $68,8 \%$ dos pacientes. Não se observou diferença, com significado estatístico, na quantidade total de marcadores retidos no $3^{\circ}$ e $5^{\circ}$ dias do exame entre os pacientes de ambos os sexos com e sem megarreto. A quantidade de marcadores, em cada segmento, colônico mostrou diferença estatística. Estes marcadores apresentaram uma distribuição em forma de um gradiente, crescendo de proximal para distal tanto no $3^{\circ}$ quanto no $5^{\circ}$ dia. Ocorreu uma progressão dos marcadores em direção ao ânus com um 
acúmulo no retossigmóide com diferença estatística do $3^{\circ}$ para $05^{\circ}$ dia. Conclusões: houve retenção quase total dos marcadores até o $5^{\circ}$ dia com predomínio no cólon esquerdo e no retossigmóide, sendo maior no retossigmóide; não houve diferença estatisticamente significante na retenção total dos marcadores entre $\circ 3^{\circ}$ e $\circ 5^{\circ}$ dia de exame; os fatores: idade, sexo, início dos sintomas, dias de constipação e megarreto não interferiram na quantidade e localização dos marcadores; os segmentos colônicos direito e esquerdo apresentaram trânsito lento, tendo ocorrido estase dos marcadores no retossigmóide. 
SUMMARY 


\section{Summary}

\section{GABRIEL NETO, S. Colonic transit time in constipated patients with chagasic megacolon. São Paulo, 2003. 56p. Dissertação (Mestrado) - Faculdade de Medicina, Universidade de São Paulo.}

Chagasic megacolon may be present in up to $10 \%$ of infected people during chronic phase of the disease. Long lasting constipation of a few days up to months is the main complaint. Phisiopathology of megacolon is not completely understood as well as the predominant dilatation of sigmoid colon. This study addressed the colonic transit time (CTT) in patients with acquired megacolon with chronic constipation grater then 8 days. Study group consisted of 64 patients ( 36 women and 28 men); age ranged from 32 to 76 years. All patients had clinical history of constipation, barium enema showing megacolon (colon diameter $\geq 6,5 \mathrm{~cm}$ ) and positive serological tests for Chagas disease. CTT was evaluated by oral administration of a capsule with 24 ring-shaped radiopaque markers (Sitzmarks, Consil Pharmaceutics, Fort Worth, USA) and plain abdominal X-Rays were taken in the $3^{\text {rd }}$ and $5^{\text {th }}$ days post capsule ingestion. Twenty patients with no colorectal complaint and negative serology for Chagas disease were submitted to the same CTT exam as a control group. Results of number and position of radiopaque markers were evaluated according to large bowel segments: right colon, left colon and rectosigmoid colon. Kolmogorov-Smirnov test was used to compare the number of markers by segments in the $3^{\text {rd }}$ and $5^{\text {th }}$ days and Wilcoxon test to compare groups by the number of markers. Pearson correlating test was applied to analyze variables as sex, age, symptoms onset (years), period of constipation (days) and megarectum association. Onset of symptoms ranged from 1 to 33 years while constipation varied from 8 to 90 days. There was not difference between the number of retained colonic markers in the $3^{\text {rd }}$ and $5^{\text {th }}$ days post administration. The number of markers in each colonic segment had significant difference statistically in the $3^{\text {rd }}$ and $5^{\text {th }}$ days with greater numbers from proximal to distal colon. Such distribution assumed an aspect of a gradient and some radiopaque markers moved towards rectosigmoid colon from $3^{\text {rd }}$ to $5^{\text {th }}$ days with difference statistically significant. Conclusions: majority of radiopaque markers was retained up to $5^{\text {th }}$ day in the left and rectosigmoid colon with greater accumulation in the rectosigmoid; sex, age, symptoms onset (years), period of constipation (days) and megarectum association had not influenced the number and position of retained markers; right an left colons showed slow transit while rectosigmoid showed fecal stasis. 


\section{INTRODUÇÃO}




\subsection{Introdução}

\subsection{A doença de Chagas}

A Tripanossomíase Americana, também conhecida como doença de Chagas, é uma zoonose causada pelo protozoário hemoflagelado Trypanosoma (Schyzotrypanum) cruzi (CHAGAS, 1909). A doença humana é restrita ao território americano, sendo encontrada desde o México até o Chile (BARRETO, 1979) (Figura 1).

A doença de Chagas é transmitida ao hospedeiro vertebrado por insetos hematófagos da subfamília triatominae, os triatomas, tendo como principal vetor o Triatoma infestans. No Brasil, ocupa como principal habitat natural a área rural das regiões centro-sul e nordeste do Brasil (MARSDEN, 1997). O hospedeiro humano é infectado através de pele ou mucosa pela inoculação de parasitos presentes nas fezes do triatoma. Atualmente, com a transmissão vetorial interrompida e sob vigilância, as vias de transmissão como a transfusional, o transplante de órgãos e a congênita têm adquirido maior importância (SCHMUNIS, 1994). A infecção tem uma fase aguda que dura até dois meses, quando o paciente pode apresentar sintomas inespecíficos. O diagnóstico da fase aguda é dado pela detecção sangüínea

do T. cruzi. O doente evolui para a fase crônica da doença e apresenta baixa parasitemia, estando, então, o diagnóstico nesta fase vinculado a testes sorológicos. Devem ser utilizados pelo menos dois testes sorológicos de princípios diferentes para a confirmação do diagnóstico. Os testes 
convencionais são a hemoaglutinação indireta a imunofluorescência indireta e o teste imunoenzimático. Estes três tipos de testes têm sido empregados no diagnóstico da infecção pelo $T$. cruzi nos últimos 25 anos, e a sua associação leva a uma sensibilidade de $100 \%$ e uma especificidade de 96,5\% (LUQUETTI, 2000).

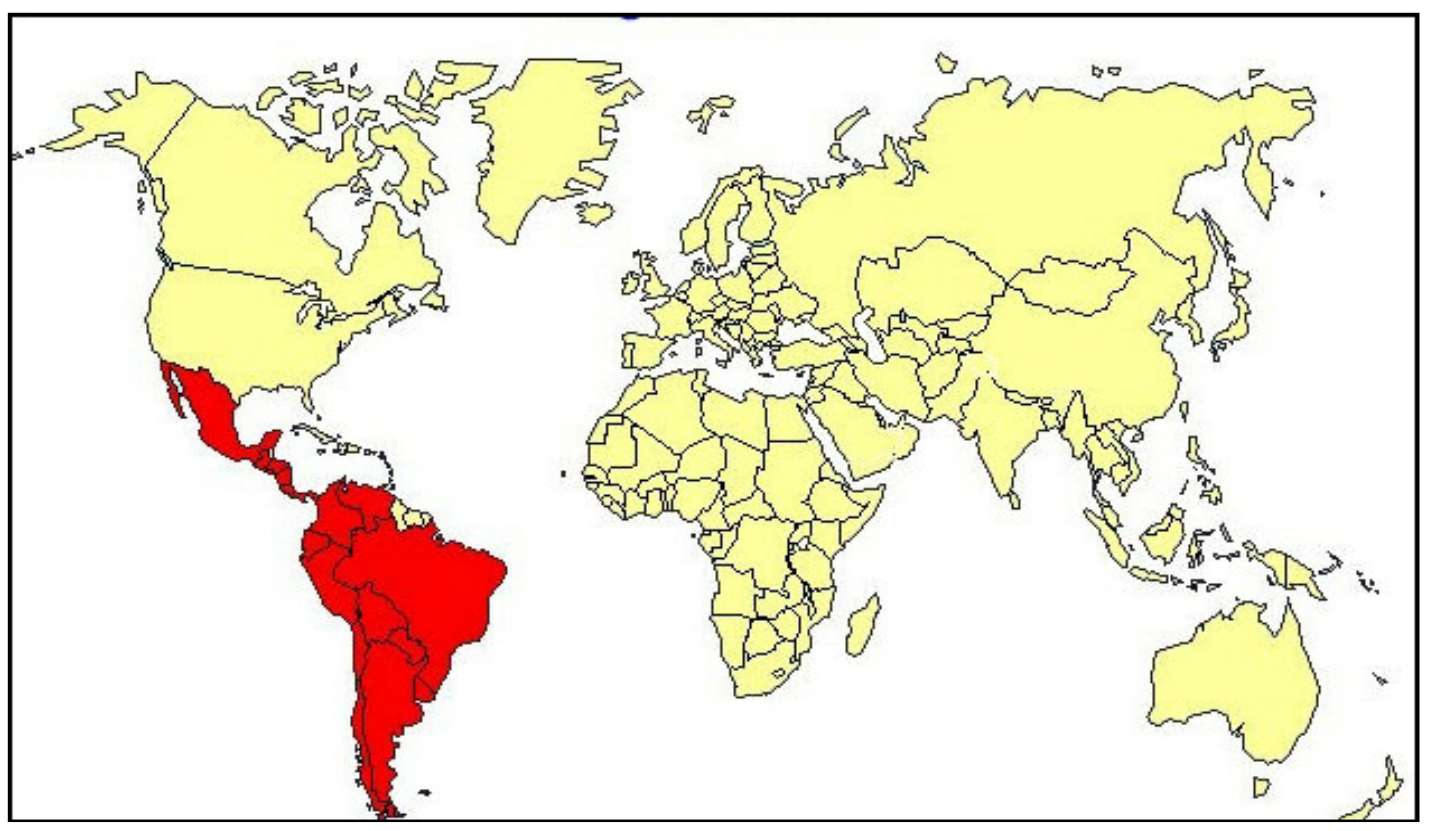

Figura 1 - Prevalência da doença de Chagas (área em vermelho)

Depois de um período assintomático que pode durar mais de 10 anos, uma porcentagem variável de pessoas, dependendo da zona geográfica, apresentará manifestações cardíacas (20-30\%) e/ou digestivas (7-10\%) (SCHMUNIS, 1994). A cardiopatia chagásica é a manifestação mais freqüente da doença, chegando a atingir, na região central do Brasil, $43 \%$ dos indivíduos chagásicos (SHERLOCK, 1979). CHAGAS, em 1911, refere que não há lesão celular enquanto o pseudocisto estiver íntegro, com a sua ruptura haveria lesão da célula hospedeira, com ativação do mecanismo de defesa celular. 
Todo o sistema nervoso autônomo pode ser atingido, porém algumas áreas são mais afetadas que outras, particularmente os segmentos distais do esôfago, o cólon e o reto, e o plexo intra-mural do coração (KÖBERLE; ALCÂNTARA, 1960; ALCÂNTARA; OLIVEIRA, 1964; KISS, 1970).

\subsection{Forma digestiva da doença de Chagas}

O acometimento do aparelho digestivo, pela doença de Chagas, ocorre predominantemente no esôfago e no cólon. Outros órgãos como, por exemplo, o duodeno e o estômago podem ser lesados pelo $T$. cruzi o que levou REZENDE (1959), a propor a denominação de forma digestiva para todas as alterações anatômicas e funcionais do aparelho digestivo causadas pela doença de Chagas.

As formas crônicas digestivas estão presentes especialmente abaixo da linha do equador, ocorrendo no Brasil a esofagopatia em cerca de $7-11 \%$ dos pacientes em áreas endêmicas, e a colopatia em 1-7\%, sendo mais baixas as prevalências para estômago e duodeno (DIAS, 2000; HERNANDEZ, 2002).

A colopatia é a mais tardia das formas crônicas, aparecendo quase sempre após os 30 anos de idade e tendo evolução lentamente progressiva, estando assim em mais de $50 \%$ dos casos, já associada à cardiopatia e à esofagopatia (RASSI et al. 1986; REZENDE; LUQUETTI 1994). São complicações do megacólon chagásico: fecaloma, volvo e perfuração (HABR-GAMA et al., 1968, 1973, 1976; KISS, 1994; MOREIRA, 2000). 
Os primeiros estudos no Brasil sobre megacólon (AMORIM; CORRÊIA NETO, 1932) descreveram em um paciente, com megaesôfago e megarreto, a presença de lesões do sistema neurovegetativo. CORRÊA NETTO, em 1934, demonstrou a destruição de plexos mioentéricos em cinco pacientes com megacólon chagásico. ETZEL (1934) e VASCONCELOS; BOTELHO (1937), descreveram as mesmas alterações da destruição neuronal no megacólon e megaesôfago chagásicos. A partir de então, surgiram na literatura nacional vários trabalhos com pesquisa em material clínico de necrópsias e em animais experimentais infectados pelo $T$. cruzi. KÖBERLE $(1956,1957,1963)$ e OKUMURA; CORRÊA NETTO (1961), demonstraram lesões difusas, em grau variável, porém freqüentes, dos plexos nervosos intramurais de Auerbach, distribuídas por todo o trato digestivo, demonstrando a relação das mega-vísceras com a diminuição quantitativa dos neurônios dos plexos mioentéricos e submucosos em todo o intestino grosso, mais evidente na porção distal e mais acentuada no reto.

KISS (1970), através de exame de microscopia eletrônica, identificou alterações morfológicas das células musculares em espécimes de megacólon, não só no reto e no sigmóide dilatados, como também nos segmentos cólicos macroscopicamente normais. Aliadas às alterações plexulares e das células musculares, têm sido notados fenômenos de autoimunidade, tanto humoral quanto celular, identificando-se anticorpos antimúsculo liso e antinervos periféricos. Por esses achados, a teoria plexular não explica, isoladamente, a fisiopatologia do megacólon chagásico. A ela 
deve ser acrescido o conceito de doença difusa, envolvendo a musculatura lisa e complexos mecanismos imunológicos (KISS et al., 1986).

VIEIRA et al. (1964, 1966), verificaram através de estudos de eletromanometria, que nos pacientes com megacólon chagásicos há hipersensibilidade muscular aos estímulos colinérgicos, não só no megacólon instalado, como também em uma fase inicial pré-ectásica.

HABR-GAMA (1966), estudando a motilidade do cólon sigmóide e do reto por eletromanometria, verificou o aumento da atividade motora do reto e sigmóide de pacientes chagásicos. A lesão motora é difusa em todo o cólon, não se limitando ao segmento ectásico. Evidenciou alteração na coordenação dos impulsos motores, havendo registro de ondas sincrônicas, ao contrário do que ocorre no cólon de indivíduos normais. A incoordenação motora leva, inicialmente, ao retardo na progressão do conteúdo fecal, hipertrofia e hiperplasia das fibras musculares lisas e progressivamente à dilatação do órgão.

HABR-GAMA et al. (1974), realizando manometria anorretocólica tanto no pré como no pós-operatório de operação de abaixamento endoanal do cólon para tratamento do megacólon, evidenciaram que tanto a incoordenação como a acalásia não se modificam, ocorrendo, entretanto, a melhora do quadro clínico de constipação após a remoção do segmento dilatado onde a estase é mais evidente. MOREIRA (1974), mostrou os mesmos resultados em estudos eletromanométricos realizados no préoperatório, registrando, porém, melhora do sincronismo após a operação de Duhamel-Haddad, estudando 24 pacientes. 


\subsection{Propedêutica da constipação}

De acordo com os critérios de Roma II, a constipação pode ser definida como sendo a presença de um ou mais dos seguintes itens com sintomas há pelo menos um ano, sem uso de laxativos e em pelo menos 25\% das evacuações: esforço evacuatório, sensação de evacuação incompleta, eliminação de fezes endurecidas ou em cíbalos ou freqüência evacuatória menor do que três evacuações por semana (SPILLER, 2000).

A história clínica e o exame físico geral e proctológico orientam o diagnóstico etiológico de afecções ou condições funcionais localizadas no intestino ou associadas a lesões sistêmicas como prolapso retal, retocele, intussuscepção reto-anal e fecaloma. O enema opaco e a colonoscopia são importantes na propedêutica inicial da constipação associada a outras doenças colorretais como diverticulose, retocolite, endometriose, carcinomas, megacólon e megarreto.

Quando estes métodos não esclarecem a etiologia da constipação ou para a avaliação da fisiopatologia, os métodos especializados de fisiologia anorretocolônica podem ser empregados. Os mais conhecidos e usados: tempo de trânsito colônico (HINTON, 1969; ARHAN, 1981), manometria anorretal (HABR-GAMA, 1974; JORGE; WEXNER, 1993), eletromiografia (PRESTON; LENNARD-JONES, 1986), tempo trânsito de intestino delgado (BOND; LEVITT,1975; JORGE et al., 1993) e defecografia (KUIJPERS, 1992). 


\subsection{Tempo de trânsito colônico}

A partir de 1907 vários métodos foram propostos com o objetivo de avaliar o tempo de trânsito: teste do hidrogênio expirado (BOND Jr.; LEVITT, 1975; JORGE et al., 1993); material farmacocinético (BENMAIR et al., 1977); cintilografia (KREVSKY et al., 1986) e radiológico (HINTON, 1969; ARHAN, 1981; JORGE; HABR-GAMA, 1991; DEVROEDE, 1993; MAGALHÃES, 1998).

Em 1969, HINTON et al., descreveram um método para medida TTC utilizando a ingestão de marcadores radiopacos compostos por drágeas de polietileno impregnadas por bário. Realizaram radiografias seriadas do abdome e acompanharam sua eliminação nas fezes. Observaram que a eliminação do primeiro marcador se fazia a partir do terceiro dia e até o quinto dia $80 \%$ dos marcadores tinham sido eliminados.

Posteriormente, o método foi aperfeiçoado tornando-se possível além da avaliação do tempo de trânsito colônico total também a do tempo de trânsito segmentar, avaliando-se, independentemente, a motilidade do cólon direito, cólon esquerdo e retossigmóide (MARTELLI et al., 1978; BECKER, 1979; ARHAN et al., 1981; CHAUSSADE et al., 1986). Isto foi conseguido através da delimitação das regiões correspondentes aos segmentos colônicos nas radiografias simples do abdômen. Basearam-se em uma linha traçada, acompanhando os processos espinhosos das vértebras lombares e, também dessa linha, partem duas linhas simétricas traçadas entre o processo espinhoso da última vértebra lombar até o estreito superior da pelve (MARTELLI et al., 1978; METCALF et al., 1987). 
Vários estudos mostraram um tempo de trânsito colônico médio total variando de 34 a 39 horas (ARHAN et al., 1981; CHAUSSADE et al., 1986; JORGE; HABR-GAMA, 1991). Em indivíduos normais, no nosso meio, JORGE; HABR-GAMA, em 1991, mostraram valores médios de tempo de trânsito $12 \pm 7$ h para o cólon direito, $14 \pm 9$ h para o cólon esquerdo e $11 \pm 9$ h para o retossigmóide.

Poucos estudos têm sido realizados em nosso meio para o megacólon chagásico. Achamos, por essa razão, importante realizar estudo prospectivo para avaliar os resultados do tempo de trânsito em portadores de megacólon ainda não operados para, posteriormente, prosseguir na investigação para avaliar os resultados cirúrgicos. 


\section{OBJETIVO}




\subsection{Objetivo}

Avaliar o tempo de trânsito colônico com marcadores radiopacos em portadores de megacólon chagásico com constipação intestinal crônica acima de oito dias. 
CASUÍSTICA E MÉTODOS 


\subsection{Casuística e métodos}

\subsection{Casuística}

Foram estudados 64 pacientes com história clínica de constipação intestinal crônica e diagnóstico radiológico por enema opaco de megacólon em pré-operatório de tratamento cirúrgico.

O enema opaco foi realizado pela técnica de duplo contraste. Foi considerado como megacólon quando o diâmetro do cólon foi $\geq 6,5 \mathrm{~cm}$ e com megarreto quando o diâmetro ântero-posterior do reto, na radiografia de perfil, foi $\geq 6,5 \mathrm{~cm}$ (PRESTON et al., 1985) (Figura 2).

A etiologia chagásica foi confirmada por três testes sorológicos: ELISA, hemoaglutinação indireta e imunofluorescência (LUQUETTI, 2000).

Os resultados dos marcadores radiopacos foram analisados em relação aos dados coletados: sexo, idade, presença de megarreto, tempo de constipação em anos e número de dias sem evacuar.

Um grupo de 20 indivíduos (10 homens e 10 mulheres), sem queixa de constipação e sorologia negativa para doença de Chagas, foi utilizado como controle.

O estudo foi aprovado pelo Comitê de Ética em Pesquisa Médica Humana e Animal do Hospital das Clínicas da Universidade Federal de Goiás e pela Comissão Ético-Científica do Departamento de Gastroenterologia da Faculdade de Medicina da Universidade de São Paulo. 
Critérios de exclusão:

- presença de fecaloma não removível;

- pacientes portadores de megaesôfago grupos IV;

- diabetes melitus;

- déficit neuropsíquico;

- incapacidade de deambular;

- etilismo;

- pacientes com prolapso retal;

- gravidez.

\subsection{Preparo do doente}

Para realização das medidas do tempo de trânsito colônico, o paciente foi orientado a seguir sua dieta habitual, recomendando-se que não houvesse a ingestão de laxativos ou que fossem utilizados supositórios ou enemas evacuadores.

\subsection{Tempo de trânsito colônico}

Utilizou-se uma cápsula contendo 24 marcadores em forma de anéis radiopacos (Sitzmarks, Consil Pharmaceutics, Fort Worth, EEUU) (Figura 3) que foi ingerida. Foram realizadas radiografias simples de abdome (ortostase) no $3^{\circ}$ e $5^{\circ}$ dias (Figura 4 ).

A interpretação da localização e contagem dos marcadores foi feita de acordo com o método descrito por MARTELLI (1978). O intestino grosso foi dividido nos segmentos: cólon direito, cólon esquerdo e retossigmóide, 
traçando-se uma linha vertical imaginária passando pelos processos espinhosos até a quinta vértebra lombar e, a partir desta, duas linhas: uma que vai até a saída da pelve à direita e outra que passa pela crista ilíaca esquerda (Figura 4). O tempo de trânsito foi analisado utilizando a média aritmética dos marcadores. A avaliação foi feita independentemente para o $3^{\circ}$ e $5^{\circ}$ dia.

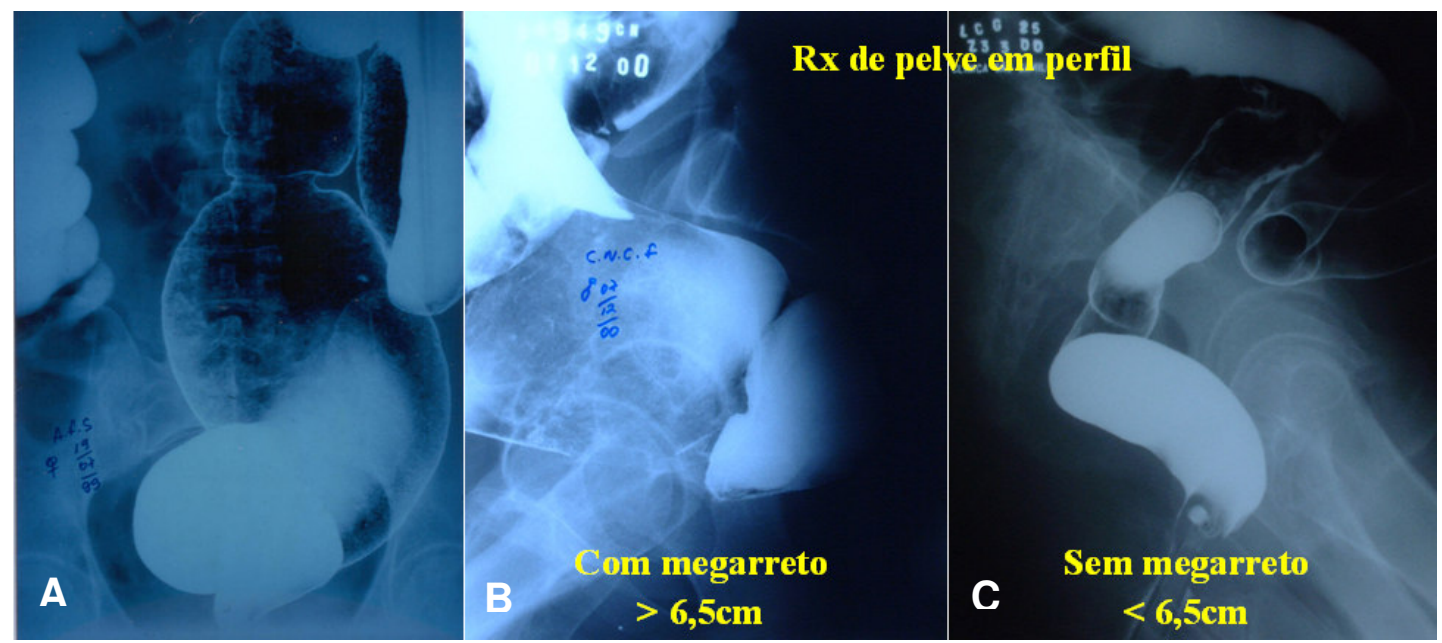

Figura 2 - A - Enema opaco de paciente com megacólon; B - Megarreto; C - Reto normal

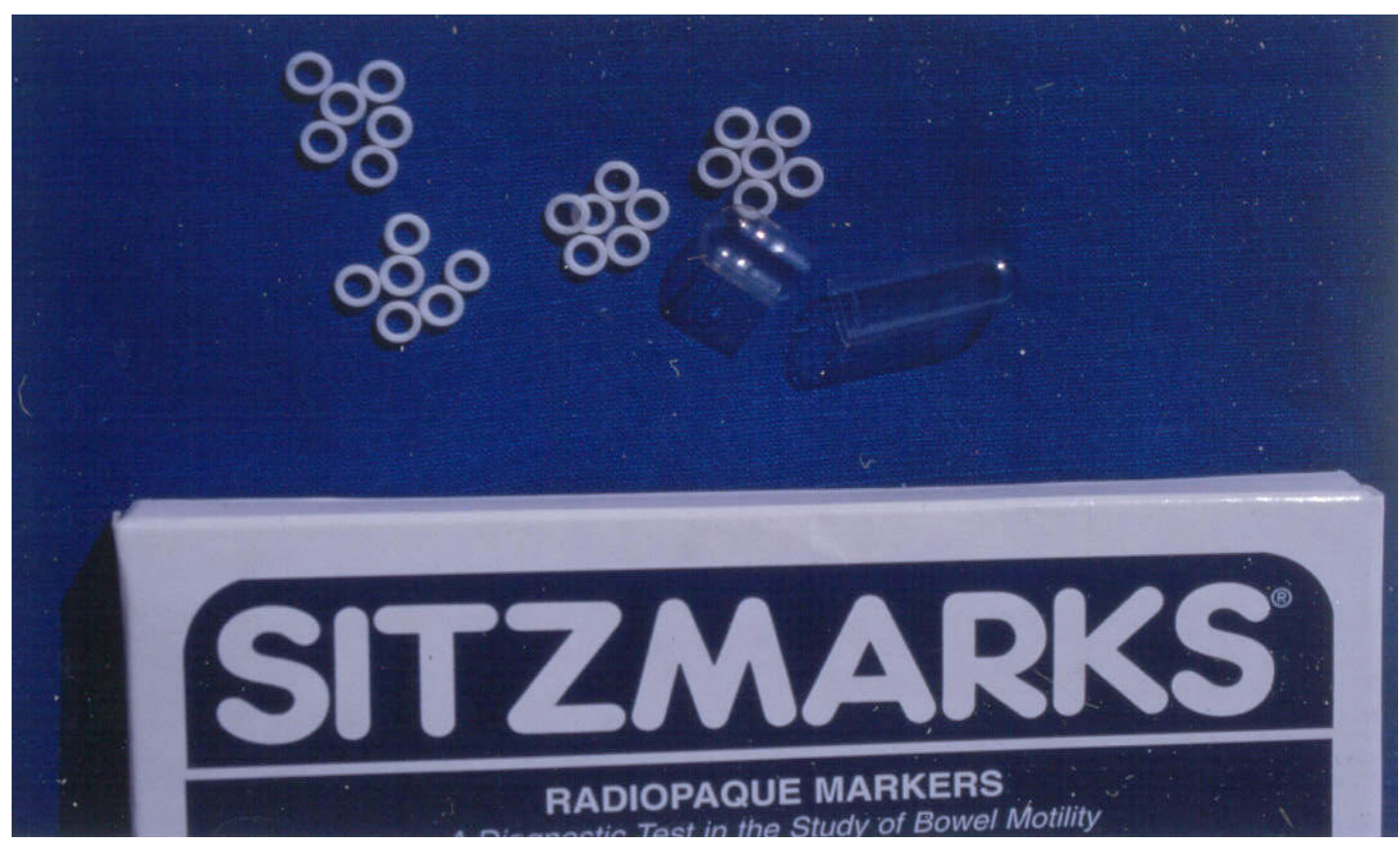

Figura 3 - Marcador radiopaco da marca Sitzmarks contendo 24 marcadores em forma de anéis por cápsula (Fort Worth, EEUU) 


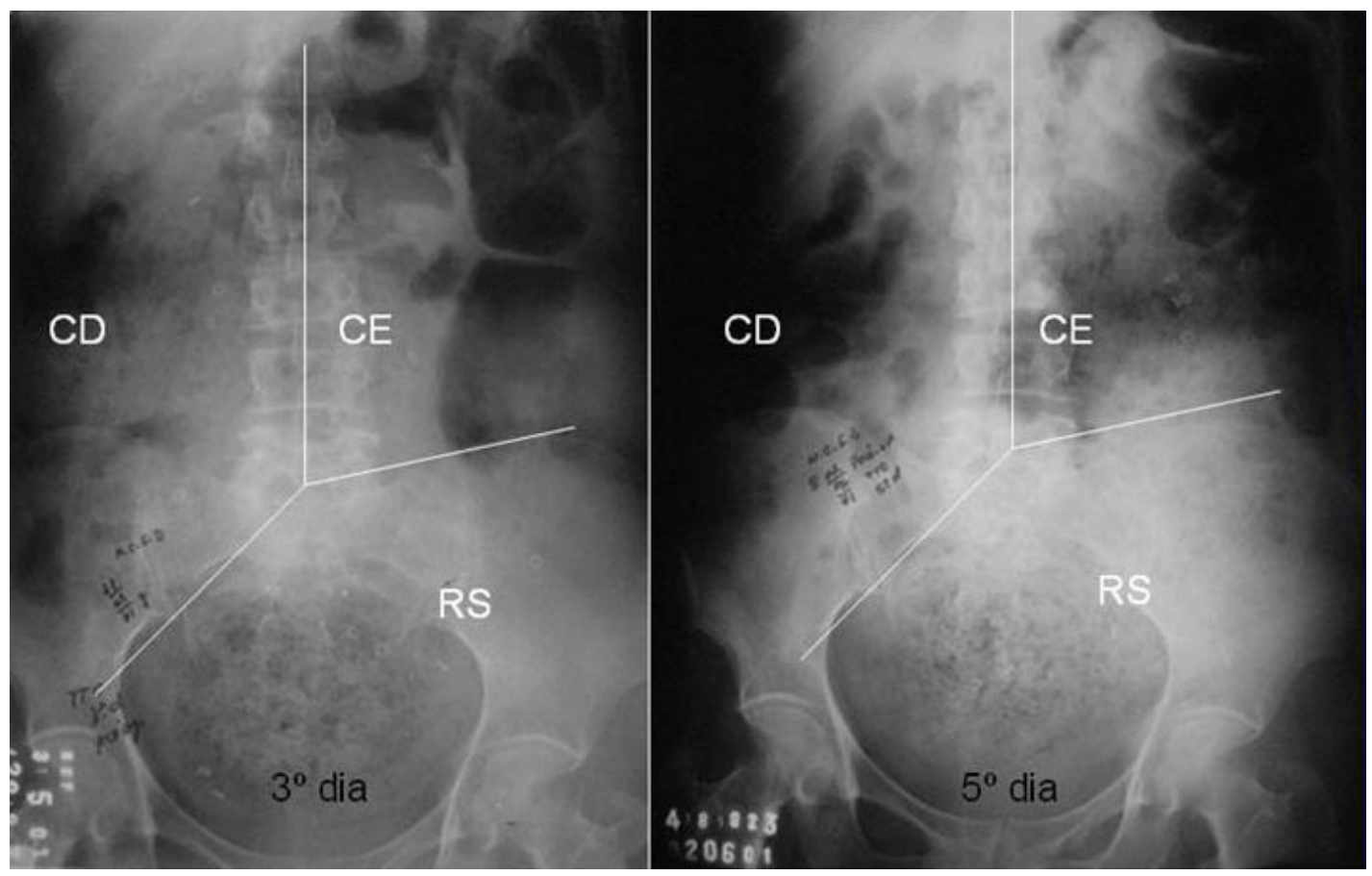

Figura 4 - Tempo de trânsito colônico no $3^{\circ}$ e $5^{\circ}$ dias do exame - As linhas mostram a divisão dos cólons: direito (CD), esquerdo (CE) e retossigmóide (RS)

\subsection{Análise estatística}

Utilizou-se o teste exato de Fisher para comparação do número de pacientes por sexo. Empregou-se o teste de Kolmogorov-Smirnov para comparação do número de marcadores em cada segmento colônico entre si e, no $3^{\circ}$ e $5^{\circ}$ dias, tanto nos doentes com megacólon quanto nos controles. O número de marcadores em cada grupo, em períodos distintos, foi avaliado com o teste de Wilcoxon. O coeficiente de correlação de Pearson foi utilizado para se avaliar a influência dos fatores externos (sexo, idade, tempo do início dos sintomas em anos, dias de constipação e presença de megarreto) no número de marcadores no $3^{\circ}$ e $5^{\circ}$ dias. 
RESULTADOS 


\subsection{Resultados}

\subsection{Pacientes com megacólon}

O grupo de pacientes estudados foi composto de 36 (56,2\%) mulheres e $28(43,8 \%)$ homens. A idade variou de 32 a 76 anos, sem diferença entre os sexos (Tabela 1).

TABELA 1 - IDADE DOS PACIENTES

\begin{tabular}{lcccc}
\hline \multicolumn{1}{c}{ SEXO } & MÉDIA & DP & MÍNIMO & MÁXIMO \\
\hline Feminino & 53,9 & 11,4 & 32 & 76 \\
Masculino & 58,0 & 9,3 & 32 & 72 \\
\hline TOTAL & $\mathbf{5 5 , 7}$ & $\mathbf{1 0 , 7}$ & $\mathbf{3 2}$ & $\mathbf{7 6}$ \\
\hline
\end{tabular}

Quanto ao tempo de início dos sintomas, variou de um a 33 anos (Tabela 2). A duração da constipação em dias variou de oito a 90 dias, sem diferença entre os sexos (Tabela 3).

A presença de megarreto ocorreu em $68,8 \%$ dos pacientes, sendo mais freqüente no sexo masculino $(82,1 \%)$ (Tabela 4), porém, não houve diferença entre os sexos com relação à presença de megarreto pelo teste de Fisher $(p=0,058)$. 
TABELA 2 - TEMPO DO INÍCIO DOS SINTOMAS (EM ANOS)

\begin{tabular}{ccccc}
\hline SEXO & MÉDIA & DESVIO PADRÃO & MÍNIMO & MÁXIMO \\
\hline Feminino & 9,1 & 7,1 & 1 & 30 \\
Masculino & 9,3 & 8,7 & 1 & 33 \\
\hline TOTAL & $\mathbf{9 , 2}$ & $\mathbf{7 , 8}$ & $\mathbf{1}$ & $\mathbf{3 3}$ \\
\hline
\end{tabular}

TABELA 3 - DIAS DE CONSTIPAÇÃO

\begin{tabular}{ccccc}
\hline SEXO & MÉDIA & DESVIO PADRÃO & MÍNIMO & MÁXIMO \\
\hline Feminino & 17,8 & 9,0 & 8 & 30 \\
Masculino & 21,5 & 17,6 & 8 & 90 \\
\hline TOTAL & $\mathbf{1 9 , 4}$ & $\mathbf{1 3 , 5}$ & $\mathbf{8}$ & $\mathbf{9 0}$ \\
\hline
\end{tabular}

TABELA 4 - DISTRIBUIÇÃO DOS PACIENTES QUANTO AO SEXO E PRESENÇA DE MEGARRETO

\begin{tabular}{crrr}
\hline \multirow{2}{*}{ SEXO } & \multicolumn{2}{c}{ MEGARRETO } & \multirow{2}{*}{ TOTAL $(\%)$} \\
\cline { 2 - 3 } & Não $(\%)$ & $\operatorname{Sim}(\%)$ & \\
\hline Feminino & $15(41,7)$ & $21(58,3)$ & $36(100)$ \\
Masculino & $5(17,9)$ & $23(82,1)$ & $28(100)$ \\
\hline TOTAL & $\mathbf{2 0 ( 3 1 , 3 )}$ & $\mathbf{4 4}(\mathbf{6 8 , 8})$ & $\mathbf{6 4 ( 1 0 0 )}$ \\
\hline
\end{tabular}

$p=0,058$

\subsection{Pacientes do grupo controle}

O grupo controle apresentou uma média de idade de 33,2 anos para as mulheres e de 28,5 anos para os homens, variando de 21 a 43 anos (Tabela 5). 
TABELA 5 - GRUPO CONTROLE: MÉDIAS E DESVIO PADRÃO PARA A IDADE

\begin{tabular}{ccccc}
\hline SEXO & MÉDIA & DESVIO PADRÃO & MÍNIMO & MÁXIMO \\
\hline Feminino & 33,2 & 8,3 & 23 & 43 \\
Masculino & 28,5 & 5,3 & 21 & 35 \\
\hline TOTAL & $\mathbf{3 0 , 8}$ & $\mathbf{7 , 2}$ & $\mathbf{2 1}$ & $\mathbf{4 3}$ \\
\hline
\end{tabular}

\subsection{Pacientes com megacólon: análise dos marcadores}

Não se observou diferença, com significado estatístico, na quantidade total de marcadores retidos no $3^{\circ}$ e $5^{\circ}$ dias do exame entre os pacientes de ambos os sexos com e sem megarreto (Tabela 6).

TABELA 6 - NÚMERO MÉDIO DE MARCADORES EM TODO O CÓLON $\mathrm{NO} 3^{\circ} \mathrm{E} 5^{\circ}$ DIAS

\begin{tabular}{|c|c|c|c|}
\hline \multirow[b]{2}{*}{ SEXO } & \multirow[b]{2}{*}{ MEGARRETO } & \multicolumn{2}{|c|}{ DIAS } \\
\hline & & $3^{\circ}$ & $5^{\circ}$ \\
\hline \multirow{2}{*}{ Feminino } & Sim & 22,52 & 21,30 \\
\hline & Não & 22,80 & 21,20 \\
\hline \multirow{2}{*}{ Masculino } & Sim & 22,30 & 22,20 \\
\hline & Não & 21,60 & 22,00 \\
\hline TOTAL & & 22,50 & 21,45 \\
\hline
\end{tabular}

$p>0,059$

A quantidade de marcadores em cada segmento colônico mostrou diferença estatística, em forma de um gradiente, crescendo de proximal para distal tanto no $3^{\circ}$ quanto no $5^{\circ}$ dia (Tabelas 7, 8 e 9; Gráficos 1, 2, 3 e 4). Ocorreu uma progressão dos marcadores em direção ao ânus com um acúmulo no retossigmóide, i.e., a quantidade de marcadores nos cólons 
direito e esquerdo apresentaram diferença estatística do $3^{\circ}$ para $\circ 5^{\circ}$ dia. Porém, a quantidade de marcadores no retossigmóide e o total retido não apresentaram diferença significativa (Tabela 10; Gráficos 1, 2, 3 e 4).

TABELA 7 - COMPARAÇÃO DO NÚMERO DE MARCADORES EM CADA SEGMENTO ENTRE SI NO $3^{\circ}$ E $5^{\circ}$ DIAS NOS DOENTES COM MEGACÓLON

\begin{tabular}{|c|c|c|c|c|}
\hline \multirow{2}{*}{ DIA } & \multirow{2}{*}{$\begin{array}{l}\text { SEGMENTO } \\
\text { COLÔNICO }\end{array}$} & \multirow{2}{*}{ MEDIANA } & \multicolumn{2}{|c|}{ ANÁLISE ESTATÍSTICA * } \\
\hline & & & Z & $p$ \\
\hline \multirow{6}{*}{$3^{\circ}$} & CD & 1,5 & \multirow{2}{*}{2,503} & \multirow{2}{*}{0,012} \\
\hline & CE & 3,5 & & \\
\hline & CD & 1,5 & \multirow{2}{*}{4,522} & \multirow{2}{*}{$<0,001$} \\
\hline & RS & 13,0 & & \\
\hline & CE & 3,5 & \multirow{2}{*}{2,905} & \multirow{2}{*}{0,004} \\
\hline & RS & 13,0 & & \\
\hline \multirow{5}{*}{$5^{\circ}$} & $\begin{array}{l}C D \\
C E\end{array}$ & $\begin{array}{l}0,0 \\
45\end{array}$ & 3,782 & $<0,001$ \\
\hline & CD & 0,0 & \multirow{2}{*}{5,439} & \multirow{2}{*}{$<0,001$} \\
\hline & RS & 14,0 & & \\
\hline & CE & 4,5 & \multirow{2}{*}{3,661} & \multirow{2}{*}{$<0,001$} \\
\hline & RS & 14,0 & & \\
\hline
\end{tabular}

* Teste de Kolmogorov-Smirnov

TABELA 8 - MÉDIAS E DESVIO PADRÃO DO NÚMERO DE MARCADORES POR SEGMENTO COLÔNICO

\begin{tabular}{ccccc}
\hline \multirow{2}{*}{ DIA } & $\begin{array}{c}\text { CÓLON } \\
\text { DIREITO }\end{array}$ & $\begin{array}{c}\text { CÓLON } \\
\text { ESQUERDO }\end{array}$ & RETOSSIGMÓIDE & EXPELIDOS \\
\hline $3^{\circ}$ & $3,8(5,6)$ & $6,7(6,7)$ & $11,9(7,8)$ & $1,5(2,3)$ \\
$5^{\circ}$ & $2,3(4,8)$ & $5,3(6,3)$ & $13(7,7)$ & $2,4(2,3)$ \\
\hline
\end{tabular}

( ) Desvio padrão 
TABELA 9 - MÉdIAS E DESVIO PADRÃO DO NÚMERO DE MARCADORES POR SEGMENTO COLÔNICO

\begin{tabular}{ccccccc}
\hline SEXO & MR & DIA & CD & CE & RS & EXP \\
\hline \multirow{5}{*}{ Feminino } & \multirow{2}{*}{ Sim } & $3^{\circ}$ & $4,1(3,8)$ & $5,3(7,3)$ & $13,1(7,1)$ & $1,5(2,8)$ \\
\cline { 2 - 7 } & & $5^{\circ}$ & $1,5(3,4)$ & $6,0(7,1)$ & $14,3(7,6)$ & $2,2(4,0)$ \\
\cline { 2 - 7 } & \multirow{2}{*}{ Não } & $3^{\circ}$ & $4,6(7,6)$ & $8,0(6,9)$ & $10,2(8,4)$ & $1,2(2,1)$ \\
& $5^{\circ}$ & $3,6(6,1)$ & $5,3(5,4)$ & $11,6(8,1)$ & $3,5(4,0)$ \\
\hline \multirow{4}{*}{ Masculino } & \multirow{2}{*}{ Sim } & $3^{\circ}$ & $3,7(6,1)$ & $6,7(5,4)$ & $12,0(7,8)$ & $1,7(2,0)$ \\
\cline { 2 - 7 } & \multirow{2}{*}{ Não } & $5^{\circ}$ & $2,6(5,3)$ & $6,0(4,7)$ & $13,0(6,9)$ & $2,4(3,0)$ \\
\hline & $3^{\circ}$ & $1,8(3,5)$ & $9,2(10,0)$ & $11,0(10,2)$ & $2,0(2,5)$ \\
& $5^{\circ}$ & $0,6(0,9)$ & $9,8(10,5)$ & $11,6(9,4)$ & $2,0(2,5)$ \\
\hline
\end{tabular}

( ) Desvio padrão

TABELA 10 - ANÁLISE ESTATÍSTICA COMPARANDO O NÚMERO DE MARCADORES NO $3^{\circ}$ E $5^{\circ}$ DIAS POR SEGMENTO COLÔNICO $(\mathrm{N}=64)$

\begin{tabular}{|c|c|c|c|c|}
\hline \multirow{2}{*}{$\begin{array}{l}\text { SEGMENTO } \\
\text { COLÔNICO }\end{array}$} & \multirow{2}{*}{ DIA } & \multirow{2}{*}{ MEDIANA } & \multicolumn{2}{|c|}{ VALORES* } \\
\hline & & & Z & $p$ \\
\hline \multirow{2}{*}{ CD } & $3^{0}$ & 1,5 & \multirow{2}{*}{3,528} & \multirow{2}{*}{$<0,001$} \\
\hline & $5^{\circ}$ & 0,0 & & \\
\hline \multirow{2}{*}{ CE } & $3^{\circ}$ & 3,5 & \multirow{2}{*}{3,762} & \multirow{2}{*}{$<0,001$} \\
\hline & $5^{\circ}$ & 4,5 & & \\
\hline \multirow{2}{*}{$\mathrm{RS}$} & $3^{\circ}$ & 13,0 & \multirow{2}{*}{0,521} & \multirow{2}{*}{0,602} \\
\hline & $5^{\circ}$ & 14,0 & & \\
\hline \multirow{2}{*}{ TOTAL } & $3^{\circ}$ & 24,0 & \multirow{2}{*}{1,229} & \multirow{2}{*}{0,219} \\
\hline & $5^{\circ}$ & 23,0 & & \\
\hline
\end{tabular}

* Teste de Wilcoxon 


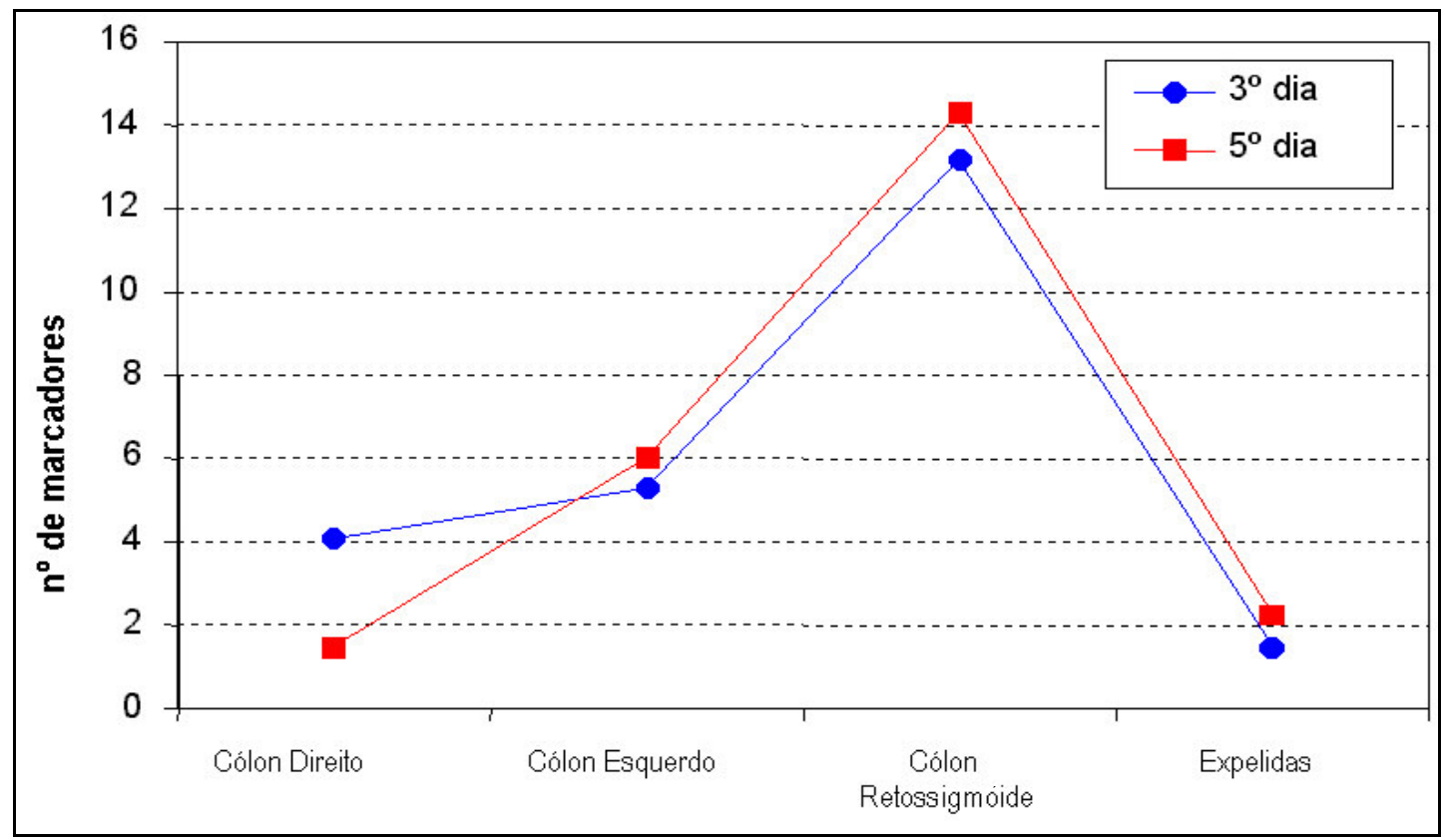

Figura 5 - Número de marcadores por segmento colônico em pacientes do sexo feminino com megarreto

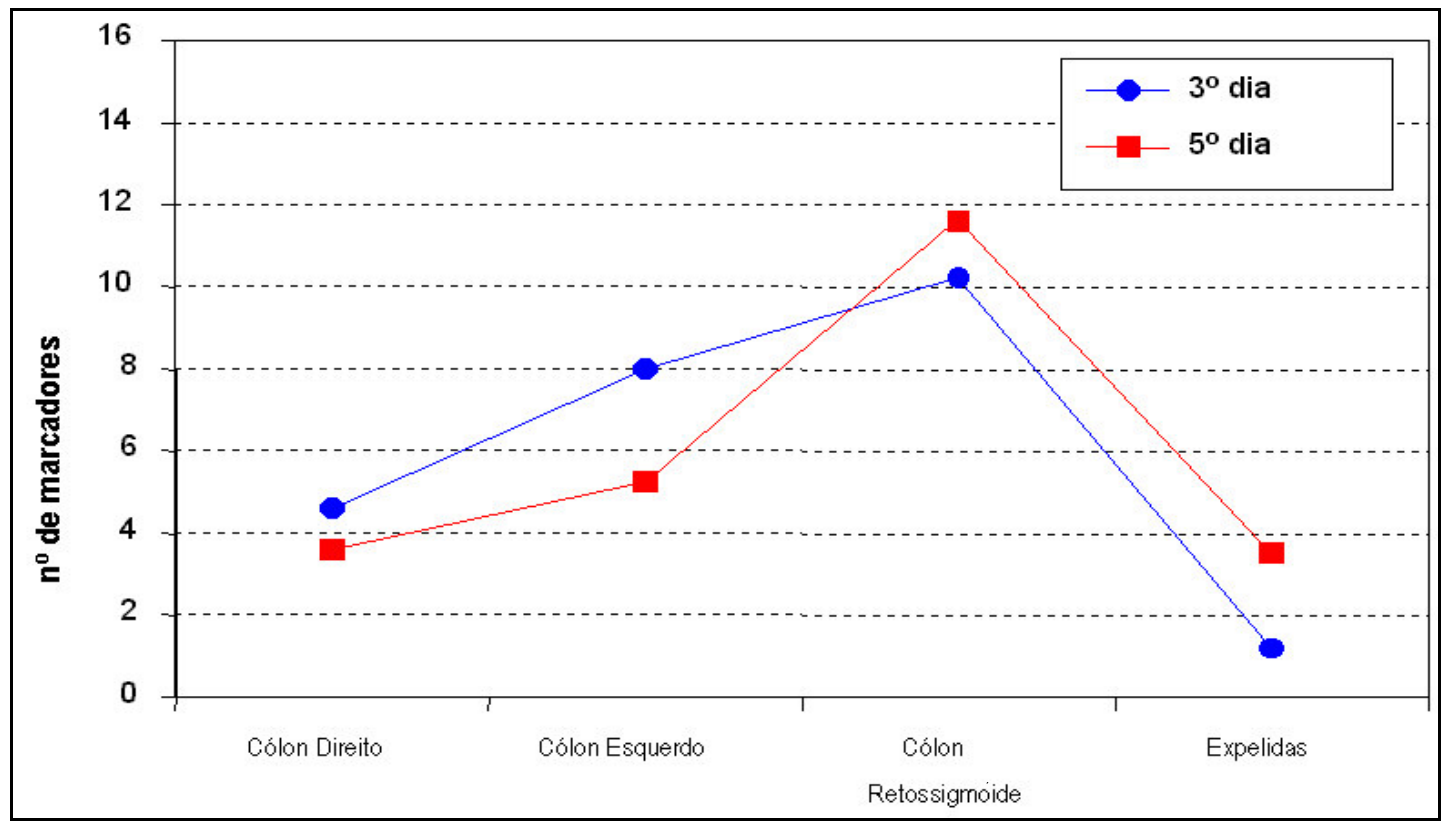

Figura 6 - Número de marcadores por segmento colônico em pacientes do sexo feminino sem megarreto 


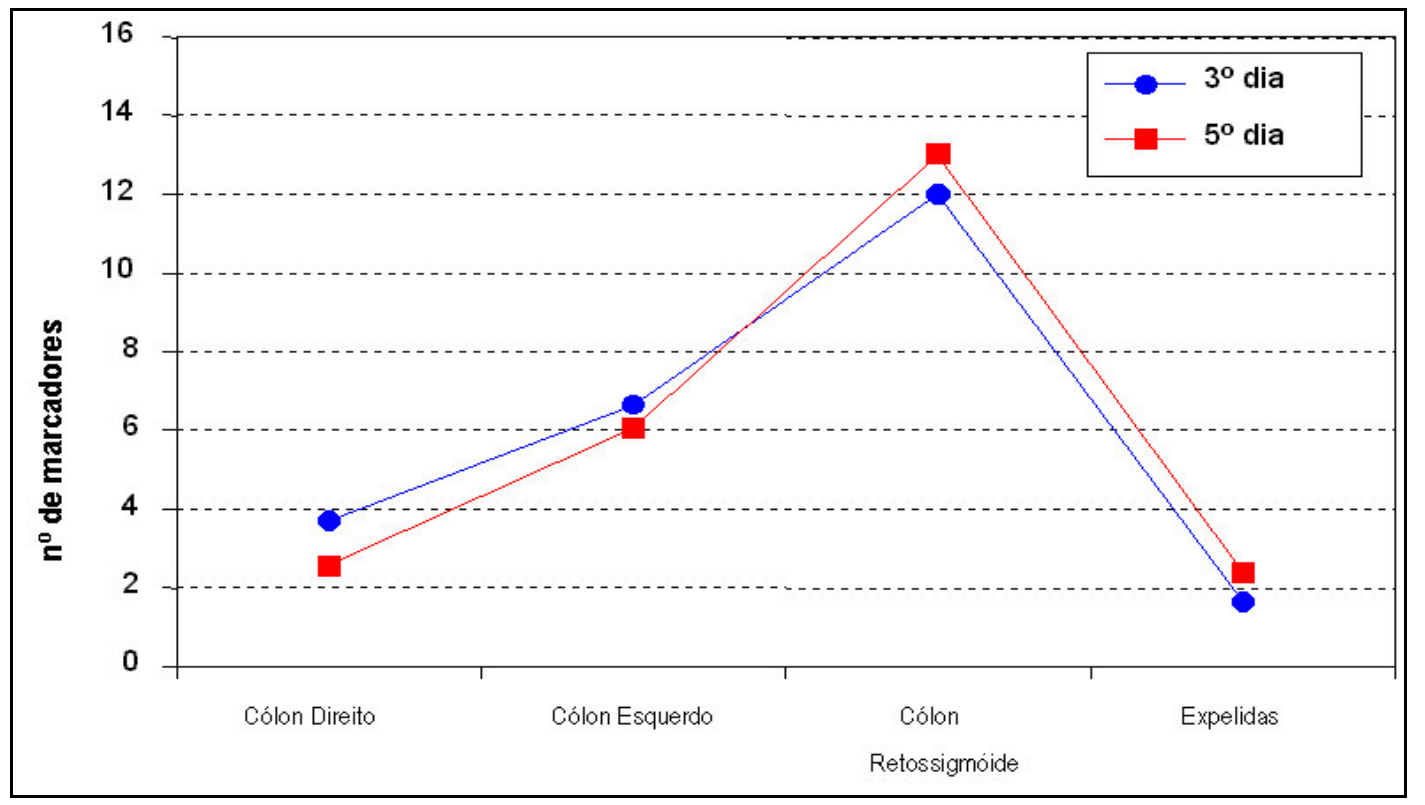

Figura 7 - Número de marcadores por segmento colônico em pacientes do sexo masculino com megarreto

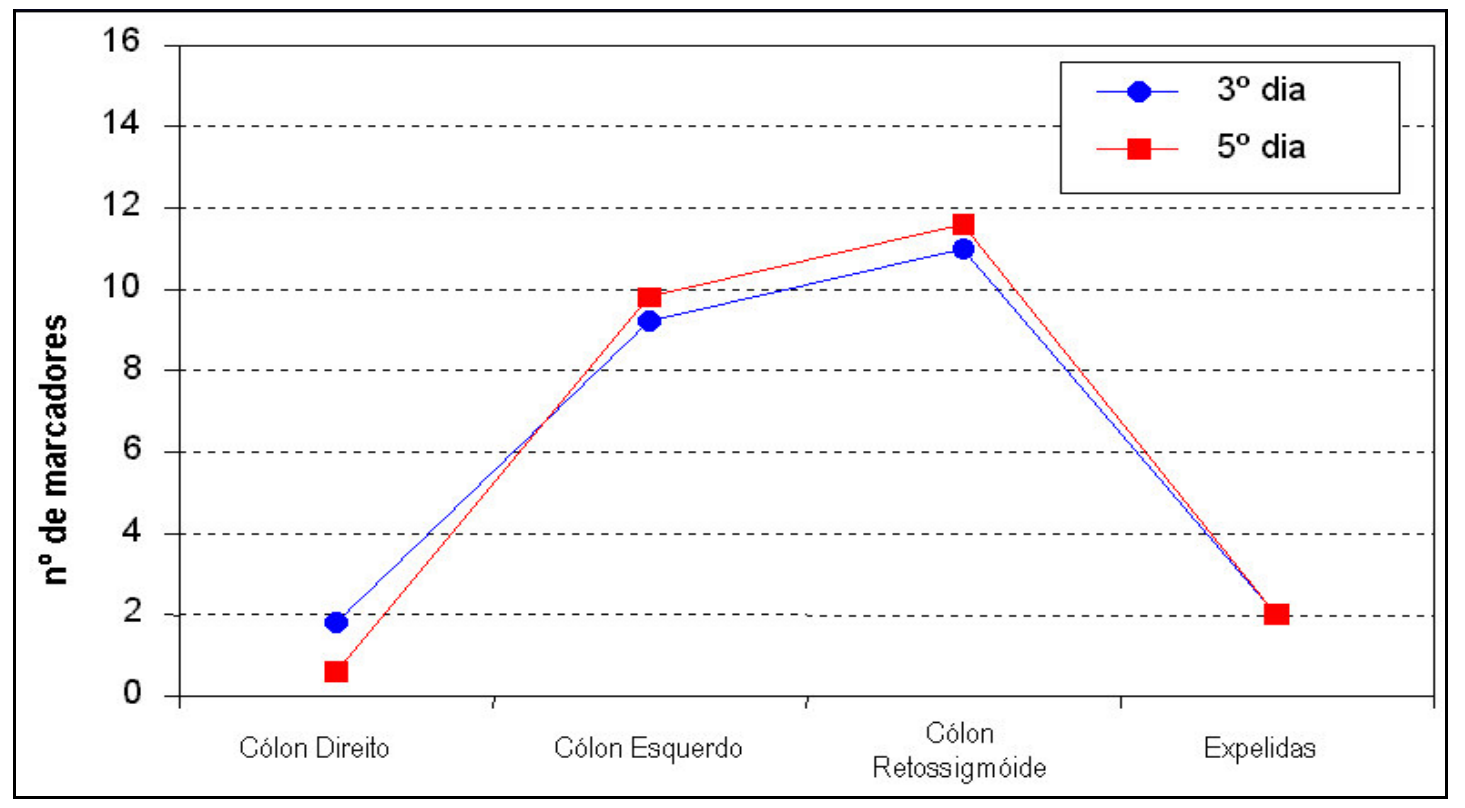

Figura 8 - Número de marcadores por segmento colônico em pacientes do sexo masculino sem megarreto 
As variáveis idade, sexo, início dos sintomas (anos), constipação (dias) e presença de megarreto não interferiram na quantidade total de marcadores retidos e sua localização nos segmentos colônicos no $5^{\circ}$ dia e no número total de retenção (Tabela 11).

TABELA 11 - ANÁLISE ESTATÍSTICA DAS VARIÁVEIS IDADE, SEXO, INÍCIO DOS SINTOMAS, DIAS DE CONSTIPAÇÃO E PRESENÇA DE MEGARRETO EM RELAÇÃO AO NÚMERO DE MARCADORES RETIDOS POR SEGMENTO COLÔNICO NOS DOENTES COM MEGACÓLON NO $3^{\circ} \mathrm{E}$ $5^{\circ}$ DIAS

\begin{tabular}{|c|c|c|c|c|c|c|}
\hline DIA & $\begin{array}{c}\text { FATOR DE } \\
\text { INFLUÊNCIA }\end{array}$ & ESTATÍSTICA & TOTAL & $C D$ & CE & RS \\
\hline \multirow{10}{*}{$3^{\circ}$} & \multirow{2}{*}{ Idade } & $r$ de Pearson & 0,068 & 0,052 & 0,360 & 0,255 \\
\hline & & $\mathrm{p}$ & 0,594 & 0,684 & $0,003^{* \star}$ & $0,042^{*}$ \\
\hline & \multirow{2}{*}{ Sexo } & r de Pearson & 0,068 & 0,084 & 0,051 & 0,006 \\
\hline & & $p$ & 0,0592 & 0,507 & 0,689 & 0,962 \\
\hline & \multirow{2}{*}{$\begin{array}{l}\text { Início dos } \\
\text { Sintomas }\end{array}$} & $r$ de Pearson & 0,068 & 0,135 & 0,002 & 0,075 \\
\hline & & $p$ & 0,594 & 0,288 & 0,990 & 0,558 \\
\hline & \multirow{2}{*}{ Constipação } & r de Pearson & 0,103 & 0,143 & 0,084 & 0,002 \\
\hline & & $p$ & 0,419 & 0,260 & 0,509 & 0,988 \\
\hline & \multirow{2}{*}{ Megarreto } & $r$ de Pearson & 0,044 & 0,001 & 0,159 & 0,128 \\
\hline & & $p$ & 0,731 & 0,993 & 0,210 & 0,312 \\
\hline \multirow{10}{*}{$5^{\circ}$} & \multirow{2}{*}{ Idade } & $r$ de Pearson & 0,110 & 0,068 & 0,143 & 0,010 \\
\hline & & $p$ & 0,387 & 0,596 & 0,260 & 0,938 \\
\hline & \multirow{2}{*}{ Sexo } & $r$ de Pearson & 0,023 & 0,015 & 0,068 & 0,000 \\
\hline & & $\mathrm{p}$ & 0,860 & 0,904 & 0,595 & 1,000 \\
\hline & \multirow{2}{*}{$\begin{array}{l}\text { Início dos } \\
\text { Sintomas }\end{array}$} & $r$ de Pearson & 0,002 & 0,199 & 0,125 & 0,026 \\
\hline & & $p$ & 0,990 & 0,115 & 0,323 & 0,840 \\
\hline & \multirow{2}{*}{ Constipação } & r de Pearson & 0,082 & 0,119 & 0,155 & 0,121 \\
\hline & & $\mathrm{p}$ & 0,519 & 0,349 & 0,220 & 0,339 \\
\hline & \multirow{2}{*}{ Megarreto } & r de Pearson & 0,039 & 0,079 & 0,018 & 0,102 \\
\hline & & $\mathrm{p}$ & 0,758 & 0,537 & 0,888 & 0,424 \\
\hline
\end{tabular}

${ }^{* *} \mathrm{p}<0,05$ 


\subsection{Grupo controle: análise dos marcadores}

No grupo controle (95\% dos pacientes), foram eliminados todos os marcadores já no $3^{\circ}$ dia (Tabelas 12 e 13).

TABELA 12 - GRUPO CONTROLE: MÉDIAS E DESVIO PADRÃO DO NÚMERO DE MARCADORES POR SEGMENTO NO $3^{\circ} \mathrm{E}$ $5^{\circ}$ DIAS

\begin{tabular}{|c|c|c|c|c|c|}
\hline SEXO & DIA & $C D$ & $\mathrm{CE}$ & $\mathrm{RS}$ & EXP \\
\hline \multirow{2}{*}{ Feminino } & $3^{0}$ & $0,0(0,0)$ & $0,7(1,9)$ & $1,9(4,4)$ & $21,4(6,2)$ \\
\hline & $5^{\circ}$ & $0,0(0,0)$ & $0,0(0,0)$ & $0,5(1,6)$ & $23,5(1,6)$ \\
\hline \multirow{2}{*}{ Masculino } & $3^{\circ}$ & $0,0(0,0)$ & $0,7(2,2)$ & $0,7(1,9)$ & $22,5(4,4)$ \\
\hline & $5^{\circ}$ & $0,0(0,0)$ & $0,0(0,0)$ & $0,0(0,0)$ & $24,0(0,0)$ \\
\hline \multirow{2}{*}{ TOTAL } & $3^{\circ}$ & $0,05(0,22)$ & $0,7(0,2)$ & $1,3(3,3)$ & $21,9(5,3)$ \\
\hline & $5^{\circ}$ & $0,0(0,0)$ & $0,0(0,0)$ & $0,25(1,1)$ & $23,7(1,1)$ \\
\hline
\end{tabular}

( ) Desvio padrão

TABELA 13 - GRUPO CONTROLE: MÉDIAS E DESVIO PADRÃO DO NÚMERO TOTAL DE MARCADORES NO $3^{\circ}$ E $5^{\circ}$ DIAS

\begin{tabular}{ccc}
\hline SEXO & $3^{\circ}$ DIA & $5^{\circ}$ DIA \\
\hline Feminino & $2,6(6,2)$ & $0,5(1,6)$ \\
Masculino & $1,5(4,4)$ & $0(0)$ \\
\hline TOTAL & $\mathbf{2 , 0 5 ( 5 , 3 )}$ & $\mathbf{0 , 2 5 ( 1 , 1 )}$ \\
\hline
\end{tabular}

( ) Desvio padrão

\subsection{Comparação entre os grupos controle e com megacólon}

A comparação da quantidade de marcadores retidos no total e em cada segmento colônico entre os grupos controle e com megacólon apresentou diferença com significado estatístico (Tabela 14). 
TABELA 14 - ANÁLISE ESTATÍSTICA COMPARANDO O NÚMERO DE MARCADORES NOS DOENTES COM MEGACÓLON E GRUPO CONTROLE NO $3^{\circ}$ E $5^{\circ}$ DIAS NOS DIFERENTES SEGMENTOS DO CÓLON

\begin{tabular}{|c|c|c|c|c|c|c|}
\hline \multirow[t]{2}{*}{ DIA } & \multirow{2}{*}{$\begin{array}{l}\text { SEGMENTO } \\
\text { DE CÓLON }\end{array}$} & \multirow{2}{*}{$\begin{array}{c}\text { GRUPO } \\
\text { COMPARATIVO }\end{array}$} & \multirow[t]{2}{*}{$\mathrm{n}$} & \multirow[t]{2}{*}{ MEDIANA } & \multicolumn{2}{|c|}{$\begin{array}{c}\text { ANÁLISE }{ }^{*} \\
\text { ESTATISTTICA }\end{array}$} \\
\hline & & & & & $z$ & $p$ \\
\hline \multirow{6}{*}{$3^{\circ}$} & \multirow{2}{*}{$C D$} & Megacólon & 64 & 1,5 & \multirow{2}{*}{2,184} & \multirow{2}{*}{$<0,001$} \\
\hline & & Controle & 20 & 0,0 & & \\
\hline & \multirow{2}{*}{ CE } & Megacólon & 64 & 3,5 & \multirow{2}{*}{2,525} & \multirow{2}{*}{$<0,001$} \\
\hline & & Controle & 20 & 0,0 & & \\
\hline & \multirow{2}{*}{ RS } & Megacólon & 64 & 13,0 & \multirow{2}{*}{2,647} & \multirow{2}{*}{$<0,001$} \\
\hline & & Controle & 20 & 0,0 & & \\
\hline & \multirow{2}{*}{ TOTAL } & Megacólon & 64 & 24,0 & \multirow{2}{*}{3,647} & \multirow{2}{*}{$<0,001$} \\
\hline & & Controle & 20 & 0,0 & & \\
\hline \multirow{6}{*}{$5^{\circ}$} & \multirow{2}{*}{$C D$} & Megacólon & 64 & 0,0 & \multirow{2}{*}{1,521} & \multirow{2}{*}{0,019} \\
\hline & & Controle & 20 & 0,0 & & \\
\hline & \multirow{2}{*}{ CE } & Megacólon & 64 & 4,5 & \multirow{2}{*}{3,050} & \multirow{2}{*}{$<0,001$} \\
\hline & & Controle & 20 & 0,0 & & \\
\hline & \multirow{2}{*}{ RS } & Megacólon & 64 & 14,0 & \multirow{2}{*}{3,281} & \multirow{2}{*}{$<0,001$} \\
\hline & & Controle & 20 & 0,0 & & \\
\hline & \multirow{2}{*}{ TOTAL } & Megacólon & 64 & 23,0 & \multirow{2}{*}{3,904} & \multirow{2}{*}{$<0,001$} \\
\hline & & Controle & 20 & 0,0 & & \\
\hline
\end{tabular}

* Teste de Kolmogorov-Smirnov 


\section{DISCUSSÃO}




\subsection{Discussão}

A constipação é um sintoma muito freqüente na população em geral, podendo corresponder até a $50 \%$ das causas de procura de auxílio médico em clínicas especializadas (SONNENBERG; $\mathrm{KOCH}, 1989$ ). O termo constipação varia muito em significado para diferentes pessoas. $O$ termo pode significar que as fezes são duras, dificuldade de expelir as fezes, disquezia, fezes calibrosas ou até mesmo fezes afiladas. Quantificar esses sintomas é muito difícil. Não obstante, a freqüência evacuatória é o parâmetro mais fácil de ser mensurado. O relato da sensação de evacuação incompleta é pouco confiável, pois a complacência retal acomoda uma ampla variação de volume (KEIGHLEY; WILLIAMS, 1998).

As causas de constipação no adulto podem ser múltiplas, fato que dificulta sua investigação. As causas congênitas são: doença de Hirschsprung, hipoganglionose, hiperganglionose, meningocele, doença de von Recklinghausen e tumores neonatais da medula espinhal ou sacral. Outras causas podem ser de origem endócrina, metabólica, intoxicação exógena, neurológica e psicogênica.

A constipação funcional compreende um grupo de desordens funcionais caracterizadas por infreqüência, dificuldade ou aparente evacuação incompleta. A partir de 1999, a constipação passou a ser conceituada de acordo com os critérios bem definidos para seu diagnóstico, designados critérios de Roma II (THOMPSON et al., 1999) como sendo um 
ou mais dos seguintes sintomas há pelo menos um ano e sem o uso de laxativos e que ocorra em mais de $25 \%$ das defecações: esforço evacuatório, fezes endurecidas, sensação de evacuação incompleta, uso de manobras manuais (e.g. digitação anal ou vaginal) ou menos de 3 evacuações por semana.

Para o diagnóstico de constipação funcional, a presença de megacólon ou megarreto deve ser afastada com a realização de enema opaco. O paciente, com diagnóstico de constipação funcional, quando avaliado por testes de fisiologia anorretal, pode ser enquadrado em um dos três grupos: inércia colônica segmentar, inércia colônica total e obstrução de saída, podendo haver uma superposição dos grupos em alguns doentes.

A avaliação funcional do paciente com megacólon chagásico, apresenta características próprias, pois, os exames complementares desenvolvidos até o presente momento, foram projetados para pacientes com constipação funcional, devido em parte a limitação da incidência da doença de Chagas à América Latina. A variedade de apresentação clínica da forma digestiva da doença de Chagas dificulta o seu enquadramento nos grupos funcionais acima mencionados. A destruição dos plexos nervosos entéricos no paciente chagásico é fato conhecido há vários anos (RAIA; CAMPOS, 1955; KÖBERLE, 1956, 1957, 1963; OKUMURA; CORRÊA NETTO, 1961). Porém, se o megacólon leva à constipação ou a constipação leva ao megacólon ainda não está bem estabelecido. $\mathrm{O}$ simples fato do paciente ter sorologia positiva para doença de Chagas não impediria que ele pudesse ser enquadrado em um dos grupos funcionais pelos critérios de 
Roma II, pois poderia ocorrer a superposição de constipação funcional em paciente soropositivo (SANTOS et al., 2000). DEVROEDE (1993) classifica a doença de Chagas como causa neurológica periférica de constipação. Porém, seria difícil classificar o paciente soropositivo com megacólon ou eliminar a superposição de um fator funcional independentemente do acometimento do cólon pela infecção crônica.

Na doença de Chagas, o megacólon pode ocorrer em até 10\% dos doentes na fase crônica; nos pacientes que apresentam constipação, essa pode durar de dias até vários meses (REZENDE; LUQUETTI, 1994). Na presente casuística não houve dificuldade de caracterizar a constipação, tendo em vista que todos os pacientes apresentaram constipação acima de oito dias, chegando a 30 dias no sexo feminino e a 90 dias para o sexo masculino. Todos tinham indicação para tratamento cirúrgico. Em relação ao tempo de constipação, em anos, variou de um a 30 anos para o sexo feminino e de um até 33 anos para o sexo masculino com média de 9,2 anos para ambos os sexos, e todos eram soro positivos para doença de Chagas. Por outro lado, aproximadamente $25 \%$ dos pacientes com diagnóstico radiológico de megacólon e sorologia positiva para doença de Chagas têm ritmo intestinal diário, tendo seu diagnóstico realizado incidentalmente ou na vigência de uma complicação aguda, o volvo, como sua primeira manifestação. Também se encontram pacientes com doença de Chagas sem megacólon com constipação de várias semanas (RASSI et al., 1986; REZENDE; LUQUETTI, 1994; HERNANDEZ, 2002). No presente trabalho, foram estudados pacientes portadores de megacólon com constipação, onde não se encontraram 
dificuldades na caracterização do megacólon ou megarreto. Do total de 64 pacientes, $20(31,3 \%)$ sem megarreto e $44(68,8 \%)$ com megarreto, sem diferença com significado estatístico para o sexos.

A motilidade colônica ainda não é bem compreendida apesar dos inúmeros estudos nesta área. A maioria das técnicas de determinação do tempo de trânsito intestinal o avalia em todo o tubo digestivo, que é o tempo que o marcador leva para percorrer o trajeto da boca ao ânus. $O$ tempo de trânsito colônico é o tempo necessário para que o marcador atravesse o intestino grosso somente. A avaliação do tempo de trânsito colônico isolado não é fácil. Para finalidade prática, estes estudos são definidos como tempo de trânsito colônico (HINTON et al., 1969; ARHAN et al., 1981; JORGE; HABR-GAMA, 1991). Esse TTC pode ser medido através da recuperação nas fezes de substâncias radioativas (KREVSKY et al., 1986), radiopacas (HINTON, 1969; ARHAN, 1981; JORGE; HABR-GAMA, 1991; DEVROEDE, 1993; MAGALHÃES, 1998) não absorvíveis, coloridas, que são utilizadas para avaliar o tempo de trânsito no trato gastrointestinal humano por inteiro.

A medida do TTC representa a forma de abordagem inicial prática e objetiva de documentar a constipação, visto que, muitos pacientes que relatam constipação de vários dias e têm tempo de trânsito colônico com resultados normais (HINTON, 1969; ARHAN et al., 1981; BOUCHOUCHA et al., 1992; DEVROEDE, 1993).

Estes são contabilizados nas fezes ou por meio da observação em radiografias simples de abdômen (HINTON, 1969; MARTELLI, 1978). O cálculo do tempo médio dos marcadores radiopacos permite distinguir o 
tempo segmentar em diferentes localizações do intestino grosso (ARHAN, 1981). Esses estudos mostram que, nem sempre, a freqüência de evacuações se correlaciona com o tempo de trânsito colorretal (VERDURON et al., 1988). Com o objetivo de se reduzir a exposição à radiação, em estudos recentes, tem sido indicada a ingestão de marcadores em três dias consecutivos, e realizar radiografias no quarto e sétimo dias de estudo em vez de exames nos quais se realizam radiografias diárias até a eliminação completa dos marcadores (METCALF et al., 1987). O método utilizado neste trabalho é o mais simples e é de fácil interpretação, requerendo a ingestão de 24 marcadores, seguida da sua quantificação em radiografias simples de abdômen. O TTC é considerado normal quando há a eliminação de pelo menos $80 \%$ dos marcadores observada na radiografia realizada no $5^{\circ}$ dia. (HINTON, 1969). Em pessoas com ritmo intestinal normal, este tempo varia de 34 a 39 horas para eliminação total dos marcadores (ARHAN et al., 1981; METCALF et al., 1986; JORGE; HABR-GAMA, 1991). No presente estudo, no grupo controle verificou-se a eliminação de $95 \%$ dos contrastes já no $3^{\circ}$ dia.

Para a avaliação segmentar do TTC, ARHAN et al. (1981), propuseram avaliar a permanência dos marcadores e a sede onde eles permanecem, ao invés de avaliar a sua eliminação. Dividiram o cólon em segmentos: direito, esquerdo e retossigmóide, traçando-se uma linha imaginária vertical na projeção dos processos espinhosos até a $5^{\underline{a}}$ vértebra lombar e, a partir destas, duas linhas que vão até a saída da pelve, em ângulo, como um $Y$ invertido e realizaram radiografias no $3^{\circ}$ e $5^{\circ}$ dias. Com esta metodologia, a dilatação do sigmóide poderia interferir na interpretação 
dos resultados por sobreposição no cólon direito e devido a isto optou-se por considerar o retossigmóide, como iniciando-se ao nível da crista ilíaca (Figura 4) (MARTELLI, 1978). Os pacientes mantiveram dieta habitual e ingeriram uma cápsula com marcadores.

A presença de fecaloma foi fator de exclusão para estudo, pela sobreposição das imagens do fecaloma sobre a do marcador. A própria radiografia utilizada para o estudo do tempo de trânsito colônico serviu de controle para os casos de fecaloma não tocável quando da realização do exame.

Analisando-se os resultados, observa-se diferença estatisticamente significante, em forma de um gradiente de retenção dos marcadores radiopacos do cólon direito ao retossigmóide. Esta proporção foi calculada pela média de retenção dos marcadores no $5^{\circ}$ dia $(C D$ 2,3/2,3 $=1 ; C E$ $5,3 / 2,3=2,3$ e RS $13 / 2,3=5,6$ ) (Tabela 6 ). Este padrão não havia sido assinalado para outras formas de constipação, nas quais ocorre uma distribuição difusa e homogênea dos marcadores ou uma concentração de marcadores em um determinado segmento colônico como na inércia colônica segmentar. A denervação mais intensa no segmento distal do cólon aos portadores da doença de Chagas poderia ser o substrato histopatológico deste padrão de retenção de marcadores.

Fazendo uma análise de regressão, não se observou correlação entre as médias do sexo, idade, tempo de início dos sintomas e dias de constipação em relação ao número total de marcadores. Este achado pode levar à interpretação de que o tempo de doença não agravaria o quadro 
clínico, conseqüentemente, em termos de manejo clínico do paciente, poderia significar indicação de intervenção terapêutica mais precoce em doentes com condições clínicas adequadas, considerando que a opção de cura para o megacólon chagásico é a cirurgia. Por outro lado, se o paciente apresentar outras manifestações da doença de Chagas, estas poderiam ser tratadas sem um agravamento do quadro colônico.

Em relação à variável sexo, este é um aspecto ainda controverso na literatura. METCALF et al. (1987), relataram um tempo de trânsito colônico menor em homens, enquanto BECKER; ELSBORG (1979) e JORGE; HABR-GAMA (1991) não encontraram esta variação. Pacientes do sexo feminino não relacionaram o início da constipação com paridade ou cirurgia pélvica (dados não mostrados), como é comumente observado (SCOTT et al. 2001).

Os resultados do presente estudo mostraram retenção de $95 \%$ dos marcadores com predomínio no cólon esquerdo e retossigmóide na avaliação do $3^{\circ}$ dia, não havendo diferença para $\circ 5^{\circ}$ dia no total de marcadores retidos. Concluiu-se com este resultado que não haveria a necessidade de se realizar a radiografia do $3^{\circ}$ dia com diminuição da exposição à radiação; se a maioria dos marcadores ingeridos pára no retossigmóide já no $3^{\circ}$ dia, a constipação do megacólon chagásico poderia ser definida como do tipo de obstrução de saída. O cólon direito e esquerdo apresentam retenção com valores significativos quando comparados com o grupo controle com média de retenção de 3,8 marcadores no $3^{\circ}$ dia e de 2,3 no $5^{\circ}$ dia, enquanto no grupo controle praticamente não houve retenção de 
marcadores. Estes resultados poderiam ter como substrato patológico a acalásia do esfíncter interno do ânus, já documentados através de estudos de eletromanometria (HABR-GAMA et al., 1970, 1974; MOREIRA, 1974). Por outro lado, os resultados satisfatórios de diferentes técnicas para o tratamento do megacólon chagásico não mostram a acalásia como fator importante para a cura da constipação (MOREIRA, 1974; HABR-GAMA et al., 1974; CUTAIT; CUTAIT, 1991).

Um achado interessante do estudo é que o tempo de doença e o número de dias de constipação não interfere no padrão de resultados. Este fato pode ser explicado pelo conhecimento que a destruição neuronal embora continue durante a fase crônica da doença, a maior destruição ocorre na fase aguda, o que fez KÖBERLE mencionar que o destino do chagásico defini-se na fase aguda (KÖBERLE, 1963; SCHMUNIS, 1994; REZENDE; LUQUETTI, 1994). Assim, poder-se-ia esperar alguma diferença entre os pacientes com pouco tempo de constipação e os pacientes com mais de 20 ou 30 anos de constipação.

Esta evolução clínica já introduz outras variáveis na avaliação da constipação, como a lesão de estruturas musculares e nervosas do assoalho pélvico, as quais foram poucos estudadas. Porém, como mencionado anteriormente, o tempo de doença não interferiu nos resultados. Isto minimizaria o fator possível de deterioração das estrutura pélvicas ou extra colônicas que integram o mecanismo da evacuação pela própria constipação. 
O presente estudo reforça esta idéia. Não foi observada a diferença entre os pacientes com e sem megarreto com relação aos marcadores e sintomas clínicos (tempo de doença, tempo de constipação em anos, sexo, idade). Porque alguns pacientes têm megarreto não está esclarecido. $\mathrm{O}$ fator dilatação parece ser uma característica da doença relacionada à interação parasito-hospedeiro.

A maioria dos estudos funcionais sobre o megacólon chagásico enfoca principalmente os resultados do tratamento cirúrgico com a ressecção do segmento dilatado e a melhora do ritmo intestinal (CUTAIT, 1965; CIPRIANOGAMA et al., 1986; HABR-GAMA et al., 1982, 1989, 1994; LINS NETO, 1997; NAHAS, 2000). Poucos estudos sobre todo o cólon como um possível órgão doente, baseando-se na fisiopatologia da doença de Chagas e que poderiam explicar porque alguns pacientes operados de megacólon continuam constipados mesmo após a ressecção do segmento dilatado (ALMEIDA, 1996).

Este trabalho abre perspectivas para novas investigações em relação à colopatia chagásica. $\mathrm{O}$ estudo em outro grupo de pacientes soropositivo com constipação acima de oito dias, porém sem megacólon, poderá permitir um paralelo entre os dois grupos. Pacientes constipados e soropositivos seriam fisiologicamente semelhantes independente da presença da dilatação? O aprofundamento deste estudo com outros grupos de pacientes poderá ter implicações clínicas importantes com relação ao tratamento precoce da colopatia chagásica. Da mesma maneira, poder-se-iam avaliar melhor os resultados funcionais do tratamento cirúrgico obtido por diferentes técnicas utilizando-se o tempo de trânsito colônico. 


\section{CONCLUSÕES}




\subsection{Conclusões}

O estudo do tempo de trânsito colônico permitiu as seguintes conclusões:

1 - Houve retenção quase total dos marcadores até no $5^{\circ}$ dia de avaliação;

2 - Os marcadores progrediram no sentido proximal para distal e houve predomínio de retenção dos marcadores no cólon esquerdo e no retossigmóide, sendo maior no retossigmóide;

3 - Não houve diferença estatisticamente significante na retenção total dos marcadores entre o $3^{\circ}$ e o $5^{\circ}$ dia de exame;

4 - Não houve influência no número de marcadores retidos bem como em sua localização pelos parâmetros investigados: idade, sexo, início dos sintomas, dias de constipação e megarreto;

5 - Os segmentos colônicos direito e esquerdo apresentaram trânsito lento, tendo ocorrido estase dos marcadores no retossigmóide. 
ANEXOS 
Anexo 1

\section{LISTA GERAL DOS PACIENTES}

\begin{tabular}{|c|c|c|c|c|c|c|c|c|c|c|c|c|c|c|}
\hline ID & PACIENTE & IDADE & SEXO & DIS & DIAS & MR & 3D & $3 C D$ & 3CE & 3RS & 5D & $5 C D$ & 5CE & 5RS \\
\hline 1 & ADS & 53 & $M$ & 6 & 60 & $\mathrm{~N}$ & 24 & 0 & 6 & 18 & 24 & 0 & 6 & 18 \\
\hline 2 & AAN & 65 & $\mathrm{M}$ & 10 & 15 & $S$ & 22 & 0 & 2 & 20 & 21 & 0 & 3 & 18 \\
\hline 3 & AFP & 63 & $M$ & 1 & 8 & $S$ & 21 & 13 & 3 & 5 & 21 & 13 & 3 & 5 \\
\hline 4 & $\mathrm{ABF}$ & 66 & $F$ & 8 & 30 & $\mathrm{~N}$ & 23 & 0 & 3 & 20 & 23 & 0 & 3 & 20 \\
\hline 5 & AFS & 49 & $\mathrm{~F}$ & 4 & 8 & $\mathrm{~N}$ & 21 & 0 & 10 & 11 & 20 & 0 & 0 & 20 \\
\hline 6 & ARS & 43 & $M$ & 5 & 15 & $S$ & 22 & 2 & 9 & 11 & 20 & 0 & 4 & 16 \\
\hline 7 & AGM & 61 & $M$ & 10 & 15 & $S$ & 24 & 3 & 13 & 8 & 24 & 1 & 9 & 14 \\
\hline 8 & AVS & 60 & $\mathrm{~F}$ & 1 & 8 & $\mathrm{~N}$ & 23 & 1 & 6 & 16 & 17 & 0 & 0 & 17 \\
\hline 9 & ARS & 67 & $M$ & 2 & 15 & $S$ & 24 & 1 & 0 & 23 & 23 & 3 & 0 & 20 \\
\hline 10 & $A C A$ & 60 & $\mathrm{~F}$ & 10 & 10 & $S$ & 24 & 1 & 3 & 20 & 24 & 1 & 3 & 20 \\
\hline 11 & ADJ & 49 & $\mathrm{~F}$ & 15 & 20 & $\mathrm{~N}$ & 16 & 0 & 13 & 3 & 15 & 0 & 11 & 4 \\
\hline 12 & ALA & 62 & $F$ & 10 & 30 & $\mathrm{~N}$ & 23 & 8 & 5 & 10 & 23 & 8 & 5 & 10 \\
\hline 13 & AFB & 52 & $M$ & 5 & 20 & $S$ & 21 & 0 & 8 & 13 & 21 & 0 & 5 & 16 \\
\hline 14 & AMD & 74 & $\mathrm{~F}$ & 1 & 8 & $S$ & 21 & 5 & 1 & 15 & 21 & 1 & 8 & 12 \\
\hline 15 & ccos & 59 & $F$ & 8 & 30 & $S$ & 24 & 1 & 3 & 20 & 24 & 0 & 4 & 20 \\
\hline 16 & $\mathrm{CMC}$ & 43 & $\mathrm{~F}$ & 1 & 8 & $\mathrm{~N}$ & 23 & 20 & 3 & 0 & 23 & 20 & 3 & 0 \\
\hline 17 & DAP & 36 & $F$ & 1 & 8 & $S$ & 24 & 6 & 14 & 4 & 24 & 0 & 0 & 24 \\
\hline 18 & DFS & 47 & $F$ & 10 & 30 & $S$ & 23 & 0 & 20 & 3 & 23 & 0 & 20 & 3 \\
\hline 19 & ECB & 32 & $M$ & 1 & 30 & $S$ & 19 & 8 & 8 & 3 & 19 & 8 & 8 & 3 \\
\hline 20 & EFS & 62 & $\mathrm{M}$ & 1 & 8 & $S$ & 24 & 3 & 5 & 16 & 24 & 4 & 9 & 11 \\
\hline 21 & EFP & 54 & $F$ & 10 & 10 & $S$ & 20 & 4 & 3 & 13 & 20 & 4 & 3 & 13 \\
\hline 22 & ERS & 46 & $F$ & 27 & 15 & $S$ & 24 & 2 & 20 & 2 & 24 & 0 & 21 & 3 \\
\hline 23 & FFB & 61 & $M$ & 3 & 10 & $S$ & 23 & 0 & 6 & 17 & 23 & 0 & 8 & 15 \\
\hline 24 & ICC & 34 & $F$ & 15 & 15 & $\mathrm{~N}$ & 24 & 3 & 15 & 6 & 23 & 1 & 0 & 22 \\
\hline 25 & IMA & 47 & $F$ & 1 & 8 & $S$ & 21 & 0 & 0 & 21 & 21 & 0 & 0 & 21 \\
\hline 26 & ILB & 74 & $\mathrm{~F}$ & 10 & 30 & $S$ & 24 & 7 & 3 & 14 & 24 & 0 & 7 & 17 \\
\hline 27 & JFC & 57 & $\mathrm{~F}$ & 20 & 30 & $\mathrm{~N}$ & 24 & 0 & 6 & 18 & 24 & 0 & 10 & 14 \\
\hline 28 & JCS & 54 & $F$ & 1 & 8 & $\mathrm{~N}$ & 24 & 5 & 19 & 0 & 24 & 5 & 19 & 0 \\
\hline 29 & JAM & 55 & $F$ & 2 & 10 & $\mathrm{~N}$ & 24 & 7 & 11 & 6 & 17 & 0 & 7 & 10 \\
\hline 30 & JSR & 67 & $M$ & 1 & 8 & $S$ & 24 & 9 & 7 & 8 & 22 & 0 & 8 & 14 \\
\hline 31 & JVS & 62 & $M$ & 4 & 15 & $S$ & 20 & 17 & 3 & 0 & 22 & 6 & 7 & 9 \\
\hline 32 & JE & 60 & $M$ & 33 & 15 & $S$ & 21 & 0 & 0 & 21 & 21 & 0 & 0 & 21 \\
\hline 33 & JJR & 64 & $M$ & 15 & 10 & $S$ & 24 & 0 & 3 & 21 & 24 & 0 & 0 & 24 \\
\hline 34 & JMF & 49 & $M$ & 12 & 29 & $\mathrm{~N}$ & 24 & 0 & 23 & 1 & 23 & 0 & 21 & 2 \\
\hline 35 & JPF & 55 & $M$ & 8 & 30 & $\mathrm{~N}$ & 21 & 0 & 0 & 21 & 21 & 0 & 0 & 21 \\
\hline 36 & JRG & 64 & $M$ & 1 & 8 & $S$ & 24 & 22 & 2 & 0 & 23 & 22 & 1 & 0 \\
\hline 37 & JZM & 72 & $M$ & 10 & 25 & $S$ & 24 & 0 & 0 & 24 & 24 & 1 & 0 & 23 \\
\hline 38 & JLJ & 52 & $F$ & 10 & 8 & $S$ & 24 & 2 & 4 & 18 & 23 & 0 & 0 & 23 \\
\hline 39 & JGC & 69 & $M$ & 20 & 90 & $S$ & 23 & 2 & 13 & 8 & 22 & 1 & 8 & 13 \\
\hline 40 & LCG & 65 & $\mathrm{~F}$ & 15 & 15 & $\mathrm{~N}$ & 24 & 24 & 0 & 0 & 17 & 14 & 3 & 0 \\
\hline
\end{tabular}


Anexo 1

LISTA GERAL DOS PACIENTES

\begin{tabular}{ccccccccccccccc}
\hline ID & PACIENTE & IDADE & SEXO & DIS & DIAS & MR & 3D & 3CD & 3CE & 3RS & 5D & 5CD & 5CE & 5RS \\
\hline 41 & LQS & 39 & $\mathrm{~F}$ & 10 & 30 & $\mathrm{~S}$ & 23 & 5 & 0 & 18 & 17 & 2 & 0 & 15 \\
42 & LGM & 67 & $\mathrm{M}$ & 30 & 10 & $\mathrm{~S}$ & 24 & 0 & 3 & 21 & 24 & 0 & 4 & 20 \\
43 & MB & 51 & $\mathrm{M}$ & 10 & 34 & $\mathrm{~S}$ & 18 & 0 & 18 & 0 & 18 & 0 & 18 & 0 \\
44 & MMAS & 40 & $\mathrm{~F}$ & 10 & 11 & $\mathrm{~N}$ & 24 & 0 & 22 & 2 & 24 & 0 & 10 & 14 \\
45 & MAN & 70 & $\mathrm{~F}$ & 1 & 8 & $\mathrm{~S}$ & 23 & 0 & 20 & 3 & 21 & 0 & 19 & 2 \\
46 & MAMC & 45 & $\mathrm{~F}$ & 4 & 15 & $\mathrm{~S}$ & 20 & 2 & 0 & 18 & 17 & 0 & 1 & 16 \\
47 & MCS & 32 & $\mathrm{~F}$ & 5 & 10 & $\mathrm{~S}$ & 24 & 0 & 0 & 24 & 24 & 0 & 0 & 24 \\
48 & MCS & 59 & $\mathrm{~F}$ & 10 & 30 & $\mathrm{~N}$ & 24 & 1 & 7 & 16 & 24 & 1 & 7 & 16 \\
49 & MRC & 63 & $\mathrm{~F}$ & 6 & 18 & $\mathrm{~S}$ & 24 & 8 & 0 & 16 & 24 & 1 & 2 & 21 \\
50 & MOGC & 44 & $\mathrm{~F}$ & 5 & 20 & $\mathrm{~S}$ & 24 & 4 & 1 & 19 & 24 & 0 & 5 & 19 \\
51 & MRS & 53 & $\mathrm{~F}$ & 4 & 15 & $\mathrm{~N}$ & 24 & 0 & 0 & 24 & 24 & 0 & 1 & 23 \\
52 & MRCC & 67 & $\mathrm{~F}$ & 8 & 20 & $\mathrm{~S}$ & 23 & 11 & 1 & 11 & 23 & 14 & 1 & 8 \\
53 & MSJ & 43 & $\mathrm{~F}$ & 20 & 30 & $\mathrm{~S}$ & 24 & 10 & 14 & 0 & 24 & 8 & 16 & 0 \\
54 & MSJ & 76 & $\mathrm{~F}$ & 15 & 30 & $\mathrm{~S}$ & 12 & 0 & 0 & 12 & 7 & 0 & 0 & 7 \\
55 & NCFD & 53 & $\mathrm{~F}$ & 10 & 15 & $\mathrm{~S}$ & 24 & 6 & 3 & 15 & 24 & 0 & 7 & 17 \\
56 & ORV & 59 & $\mathrm{~F}$ & 10 & 20 & $\mathrm{~N}$ & 21 & 0 & 0 & 21 & 20 & 0 & 2 & 18 \\
57 & OAO & 52 & $\mathrm{M}$ & 15 & 15 & $\mathrm{~S}$ & 24 & 2 & 16 & 6 & 24 & 0 & 15 & 9 \\
58 & RJA & 47 & $\mathrm{M}$ & 1 & 8 & $\mathrm{~S}$ & 24 & 0 & 16 & 8 & 24 & 0 & 10 & 14 \\
59 & SFS & 47 & $\mathrm{M}$ & 5 & 30 & $\mathrm{~S}$ & 18 & 0 & 9 & 9 & 18 & 0 & 9 & 9 \\
60 & SLG & 49 & $\mathrm{M}$ & 5 & 20 & $\mathrm{~N}$ & 24 & 8 & 16 & 0 & 24 & 2 & 21 & 1 \\
61 & SFA & 67 & $\mathrm{M}$ & 25 & 15 & $\mathrm{~N}$ & 18 & 1 & 1 & 16 & 18 & 1 & 1 & 16 \\
62 & VPM & 62 & $\mathrm{M}$ & 10 & 30 & $\mathrm{~S}$ & 22 & 1 & 7 & 14 & 11 & 0 & 4 & 7 \\
63 & VMG & 53 & $\mathrm{~F}$ & 30 & 30 & $\mathrm{~S}$ & 23 & 12 & 1 & 10 & 24 & 0 & 9 & 15 \\
64 & VFO & 62 & $\mathrm{M}$ & 10 & 15 & $\mathrm{~S}$ & 24 & 2 & 2 & 20 & 24 & 0 & 6 & 18 \\
\hline & & & & & & & & & & & & & \\
\hline
\end{tabular}


Anexo 2

\section{PACIENTES DO SEXO FEMININO}

\begin{tabular}{|c|c|c|c|c|c|c|c|c|c|c|c|c|c|}
\hline ID & PACIENTE & IDADE & DIS & DIAS & MR & $3 \mathrm{D}$ & $3 C D$ & $3 \mathrm{CE}$ & $3 R S$ & $5 \mathrm{D}$ & $5 C D$ & $5 \mathrm{CE}$ & $5 R S$ \\
\hline 4 & ABF & 66 & 8 & 30 & $\mathrm{~N}$ & 23 & 0 & 3 & 20 & 23 & 0 & 3 & 20 \\
\hline 5 & AFS & 49 & 4 & 8 & $\mathrm{~N}$ & 21 & 0 & 10 & 11 & 20 & 0 & 0 & 20 \\
\hline 8 & AVS & 60 & 1 & 8 & $\mathrm{~N}$ & 23 & 1 & 6 & 16 & 17 & 0 & 0 & 17 \\
\hline 10 & ACA & 60 & 10 & 10 & S & 24 & 1 & 3 & 20 & 24 & 1 & 3 & 20 \\
\hline 11 & ADJ & 49 & 15 & 20 & $\mathrm{~N}$ & 16 & 0 & 13 & 3 & 15 & 0 & 11 & 4 \\
\hline 12 & ALA & 62 & 10 & 30 & $\mathrm{~N}$ & 23 & 8 & 5 & 10 & 23 & 8 & 5 & 10 \\
\hline 14 & AMD & 74 & 1 & 8 & $S$ & 21 & 5 & 1 & 15 & 21 & 1 & 8 & 12 \\
\hline 15 & ccos & 59 & 8 & 30 & $S$ & 24 & 1 & 3 & 20 & 24 & 0 & 4 & 20 \\
\hline 16 & CMC & 43 & 1 & 8 & $\mathrm{~N}$ & 23 & 20 & 3 & 0 & 23 & 20 & 3 & 0 \\
\hline 17 & DAP & 36 & 1 & 8 & $S$ & 24 & 6 & 14 & 4 & 24 & 0 & 0 & 24 \\
\hline 18 & DFS & 47 & 10 & 30 & $S$ & 23 & 0 & 20 & 3 & 23 & 0 & 20 & 3 \\
\hline 21 & EFP & 54 & 10 & 10 & $S$ & 20 & 4 & 3 & 13 & 20 & 4 & 3 & 13 \\
\hline 22 & ERS & 46 & 27 & 15 & $S$ & 24 & 2 & 20 & 2 & 24 & 0 & 21 & 3 \\
\hline 24 & ICC & 34 & 15 & 15 & $\mathrm{~N}$ & 24 & 3 & 15 & 6 & 23 & 1 & 0 & 22 \\
\hline 25 & IMA & 47 & 1 & 8 & $S$ & 21 & 0 & 0 & 21 & 21 & 0 & 0 & 21 \\
\hline 26 & ILB & 74 & 10 & 30 & S & 24 & 7 & 3 & 14 & 24 & 0 & 7 & 17 \\
\hline 27 & JFC & 57 & 20 & 30 & $\mathrm{~N}$ & 24 & 0 & 6 & 18 & 24 & 0 & 10 & 14 \\
\hline 28 & JCS & 54 & 1 & 8 & $\mathrm{~N}$ & 24 & 5 & 19 & 0 & 24 & 5 & 19 & 0 \\
\hline 29 & JAM & 55 & 2 & 10 & $\mathrm{~N}$ & 24 & 7 & 11 & 6 & 17 & 0 & 7 & 10 \\
\hline 38 & JLJ & 52 & 10 & 8 & S & 24 & 2 & 4 & 18 & 23 & 0 & 0 & 23 \\
\hline 40 & LCG & 65 & 15 & 15 & $\mathrm{~N}$ & 24 & 24 & 0 & 0 & 17 & 14 & 3 & 0 \\
\hline 41 & LQS & 39 & 10 & 30 & S & 23 & 5 & 0 & 18 & 17 & 2 & 0 & 15 \\
\hline 44 & MMAS & 40 & 10 & 11 & $\mathrm{~N}$ & 24 & 0 & 22 & 2 & 24 & 0 & 10 & 14 \\
\hline 45 & MAN & 70 & 1 & 8 & $S$ & 23 & 0 & 20 & 3 & 21 & 0 & 19 & 2 \\
\hline 46 & MAMC & 45 & 4 & 15 & S & 20 & 2 & 0 & 18 & 17 & 0 & 1 & 16 \\
\hline 47 & MCS & 32 & 5 & 10 & S & 24 & 0 & 0 & 24 & 24 & 0 & 0 & 24 \\
\hline 48 & MCS & 59 & 10 & 30 & $\mathrm{~N}$ & 24 & 1 & 7 & 16 & 24 & 1 & 7 & 16 \\
\hline 49 & MRC & 63 & 6 & 18 & $S$ & 24 & 8 & 0 & 16 & 24 & 1 & 2 & 21 \\
\hline 50 & MOGC & 44 & 5 & 20 & $S$ & 24 & 4 & 1 & 19 & 24 & 0 & 5 & 19 \\
\hline 51 & MRS & 53 & 4 & 15 & $\mathrm{~N}$ & 24 & 0 & 0 & 24 & 24 & 0 & 1 & 23 \\
\hline 52 & MRCC & 67 & 8 & 20 & $S$ & 23 & 11 & 1 & 11 & 23 & 14 & 1 & 8 \\
\hline 53 & MSJ & 43 & 20 & 30 & $S$ & 24 & 10 & 14 & 0 & 24 & 8 & 16 & 0 \\
\hline 54 & MSJ & 76 & 15 & 30 & $S$ & 12 & 0 & 0 & 12 & 7 & 0 & 0 & 7 \\
\hline 55 & NCFD & 53 & 10 & 15 & $S$ & 24 & 6 & 3 & 15 & 24 & 0 & 7 & 17 \\
\hline 56 & ORV & 59 & 10 & 20 & $\mathrm{~N}$ & 21 & 0 & 0 & 21 & 20 & 0 & 2 & 18 \\
\hline 63 & VMG & 53 & 30 & 30 & S & 23 & 12 & 1 & 10 & 24 & 0 & 9 & 15 \\
\hline
\end{tabular}




\section{Anexo 3}

\section{PACIENTES DO SEXO MASCULINO}

\begin{tabular}{cccccccccccccc}
\hline ID & PACIENTE & IDADE & DIS & DIAS & MR & $3 D$ & $3 C D$ & $3 C E$ & $3 R S$ & $5 D$ & $5 C D$ & $5 C E$ & $5 R S$ \\
\hline 1 & ADS & 53 & 6 & 60 & $\mathrm{~N}$ & 24 & 0 & 6 & 18 & 24 & 0 & 6 & 18 \\
2 & AAN & 65 & 10 & 15 & $\mathrm{~S}$ & 22 & 0 & 2 & 20 & 21 & 0 & 3 & 18 \\
3 & AFP & 63 & 1 & 8 & $\mathrm{~S}$ & 21 & 13 & 3 & 5 & 21 & 13 & 3 & 5 \\
6 & ARS & 43 & 5 & 15 & $\mathrm{~S}$ & 22 & 2 & 9 & 11 & 20 & 0 & 4 & 16 \\
7 & AGM & 61 & 10 & 15 & $\mathrm{~S}$ & 24 & 3 & 13 & 8 & 24 & 1 & 9 & 14 \\
9 & ARS & 67 & 2 & 15 & $\mathrm{~S}$ & 24 & 1 & 0 & 23 & 23 & 3 & 0 & 20 \\
13 & AFB & 52 & 5 & 20 & $\mathrm{~S}$ & 21 & 0 & 8 & 13 & 21 & 0 & 5 & 16 \\
19 & ECB & 32 & 1 & 30 & $\mathrm{~S}$ & 19 & 8 & 8 & 3 & 19 & 8 & 8 & 3 \\
20 & EFS & 62 & 1 & 8 & $\mathrm{~S}$ & 24 & 3 & 5 & 16 & 24 & 4 & 9 & 11 \\
23 & FFB & 61 & 3 & 10 & $\mathrm{~S}$ & 23 & 0 & 6 & 17 & 23 & 0 & 8 & 15 \\
30 & JSR & 67 & 1 & 8 & $\mathrm{~S}$ & 24 & 9 & 7 & 8 & 22 & 0 & 8 & 14 \\
31 & JVS & 62 & 4 & 15 & $\mathrm{~S}$ & 20 & 17 & 3 & 0 & 22 & 6 & 7 & 9 \\
32 & JE & 60 & 33 & 15 & $\mathrm{~S}$ & 21 & 0 & 0 & 21 & 21 & 0 & 0 & 21 \\
33 & JJR & 64 & 15 & 10 & $\mathrm{~S}$ & 24 & 0 & 3 & 21 & 24 & 0 & 0 & 24 \\
34 & JMF & 49 & 12 & 29 & $\mathrm{~N}$ & 24 & 0 & 23 & 1 & 23 & 0 & 21 & 2 \\
35 & JPF & 55 & 8 & 30 & $\mathrm{~N}$ & 21 & 0 & 0 & 21 & 21 & 0 & 0 & 21 \\
36 & JRG & 64 & 1 & 8 & $\mathrm{~S}$ & 24 & 22 & 2 & 0 & 23 & 22 & 1 & 0 \\
37 & JZM & 72 & 10 & 25 & $\mathrm{~S}$ & 24 & 0 & 0 & 24 & 24 & 1 & 0 & 23 \\
39 & JGC & 69 & 20 & 90 & $\mathrm{~S}$ & 23 & 2 & 13 & 8 & 22 & 1 & 8 & 13 \\
42 & LGM & 67 & 30 & 10 & $\mathrm{~S}$ & 24 & 0 & 3 & 21 & 24 & 0 & 4 & 20 \\
43 & MB & 51 & 10 & 34 & $\mathrm{~S}$ & 18 & 0 & 18 & 0 & 18 & 0 & 18 & 0 \\
57 & OAO & 52 & 15 & 15 & $\mathrm{~S}$ & 24 & 2 & 16 & 6 & 24 & 0 & 15 & 9 \\
58 & RJA & 47 & 1 & 8 & $\mathrm{~S}$ & 24 & 0 & 16 & 8 & 24 & 0 & 10 & 14 \\
59 & SFS & 47 & 5 & 30 & $\mathrm{~S}$ & 18 & 0 & 9 & 9 & 18 & 0 & 9 & 9 \\
60 & SLG & 49 & 5 & 20 & $\mathrm{~N}$ & 24 & 8 & 16 & 0 & 24 & 2 & 21 & 1 \\
61 & SFA & 67 & 25 & 15 & $\mathrm{~N}$ & 18 & 1 & 1 & 16 & 18 & 1 & 1 & 16 \\
62 & VPM & 62 & 10 & 30 & $\mathrm{~S}$ & 22 & 1 & 7 & 14 & 11 & 0 & 4 & 7 \\
64 & VFO & 62 & 10 & 15 & $\mathrm{~S}$ & 24 & 2 & 2 & 20 & 24 & 0 & 6 & 18 \\
\hline & & & & & & & & & & & &
\end{tabular}




\section{Anexo 4}

\section{PACIENTES DO SEXO FEMININO SEM MEGARRETO}

\begin{tabular}{ccccccccccccc}
\hline ID & PACIENTE & IDADE & DIS & DIAS & $3 \mathrm{D}$ & $3 \mathrm{CD}$ & $3 \mathrm{CE}$ & $3 \mathrm{RS}$ & $5 \mathrm{D}$ & $5 \mathrm{CD}$ & $5 \mathrm{CE}$ & $5 \mathrm{RS}$ \\
\hline 4 & ABF & 66 & 8 & 30 & 23 & 0 & 3 & 20 & 23 & 0 & 3 & 20 \\
5 & AFS & 49 & 4 & 8 & 21 & 0 & 10 & 11 & 20 & 0 & 0 & 20 \\
8 & AVS & 60 & 1 & 8 & 23 & 1 & 6 & 16 & 17 & 0 & 0 & 17 \\
11 & ADJ & 49 & 15 & 20 & 16 & 0 & 13 & 3 & 15 & 0 & 11 & 4 \\
12 & ALA & 62 & 10 & 30 & 23 & 8 & 5 & 10 & 23 & 8 & 5 & 10 \\
16 & CMC & 43 & 1 & 8 & 23 & 20 & 3 & 0 & 23 & 20 & 3 & 0 \\
24 & ICC & 34 & 15 & 15 & 24 & 3 & 15 & 6 & 23 & 1 & 0 & 22 \\
27 & JFC & 57 & 20 & 30 & 24 & 0 & 6 & 18 & 24 & 0 & 10 & 14 \\
28 & JCS & 54 & 1 & 8 & 24 & 5 & 19 & 0 & 24 & 5 & 19 & 0 \\
29 & JAM & 55 & 2 & 10 & 24 & 7 & 11 & 6 & 17 & 0 & 7 & 10 \\
40 & LCG & 65 & 15 & 15 & 24 & 24 & 0 & 0 & 17 & 14 & 3 & 0 \\
44 & MMAS & 40 & 10 & 11 & 24 & 0 & 22 & 2 & 24 & 0 & 10 & 14 \\
48 & MCS & 59 & 10 & 30 & 24 & 1 & 7 & 16 & 24 & 1 & 7 & 16 \\
51 & MRS & 53 & 4 & 15 & 24 & 0 & 0 & 24 & 24 & 0 & 1 & 23 \\
56 & ORV & 59 & 10 & 20 & 21 & 0 & 0 & 21 & 20 & 0 & 2 & 18 \\
\hline
\end{tabular}




\section{Anexo 5}

\section{PACIENTES DO SEXO FEMININO COM MEGARRETO}

\begin{tabular}{lcccccccccccc}
\hline ID & PACIENTE & IDADE & DIS & DIAS & $3 D$ & $3 C D$ & $3 C E$ & $3 R S$ & $5 D$ & $5 C D$ & $5 C E$ & $5 R S$ \\
\hline 10 & ACA & 60 & 10 & 10 & 24 & 1 & 3 & 20 & 24 & 1 & 3 & 20 \\
14 & AMD & 74 & 1 & 8 & 21 & 5 & 1 & 15 & 21 & 1 & 8 & 12 \\
15 & CCOS & 59 & 8 & 30 & 24 & 1 & 3 & 20 & 24 & 0 & 4 & 20 \\
17 & DAP & 36 & 1 & 8 & 24 & 6 & 14 & 4 & 24 & 0 & 0 & 24 \\
18 & DFS & 47 & 10 & 30 & 23 & 0 & 20 & 3 & 23 & 0 & 20 & 3 \\
21 & EFP & 54 & 10 & 10 & 20 & 4 & 3 & 13 & 20 & 4 & 3 & 13 \\
22 & ERS & 46 & 27 & 15 & 24 & 2 & 20 & 2 & 24 & 0 & 21 & 3 \\
25 & IMA & 47 & 1 & 8 & 21 & 0 & 0 & 21 & 21 & 0 & 0 & 21 \\
26 & ILB & 74 & 10 & 30 & 24 & 7 & 3 & 14 & 24 & 0 & 7 & 17 \\
38 & JLJ & 52 & 10 & 8 & 24 & 2 & 4 & 18 & 23 & 0 & 0 & 23 \\
41 & LQS & 39 & 10 & 30 & 23 & 5 & 0 & 18 & 17 & 2 & 0 & 15 \\
45 & MAN & 70 & 1 & 8 & 23 & 0 & 20 & 3 & 21 & 0 & 19 & 2 \\
46 & MAMC & 45 & 4 & 15 & 20 & 2 & 0 & 18 & 17 & 0 & 1 & 16 \\
47 & MCS & 32 & 5 & 10 & 24 & 0 & 0 & 24 & 24 & 0 & 0 & 24 \\
49 & MRC & 63 & 6 & 18 & 24 & 8 & 0 & 16 & 24 & 1 & 2 & 21 \\
50 & MOGC & 44 & 5 & 20 & 24 & 4 & 1 & 19 & 24 & 0 & 5 & 19 \\
52 & MRCC & 67 & 8 & 20 & 23 & 11 & 1 & 11 & 23 & 14 & 1 & 8 \\
53 & MSJ & 43 & 20 & 30 & 24 & 10 & 14 & 0 & 24 & 8 & 16 & 0 \\
54 & MSJ & 76 & 15 & 30 & 12 & 0 & 0 & 12 & 7 & 0 & 0 & 7 \\
55 & NCFD & 53 & 10 & 15 & 24 & 6 & 3 & 15 & 24 & 0 & 7 & 17 \\
63 & VMG & 53 & 30 & 30 & 23 & 12 & 1 & 10 & 24 & 0 & 9 & 15 \\
\hline
\end{tabular}


Anexo 6

PACIENTES DO SEXO MASCULINO SEM MEGARRETO

\begin{tabular}{ccccccccccccc}
\hline ID & PACIENTE & IDADE & DIS & DIAS & $3 \mathrm{D}$ & $3 \mathrm{CD}$ & $3 \mathrm{CE}$ & $3 \mathrm{RS}$ & $5 \mathrm{D}$ & $5 \mathrm{CD}$ & $5 \mathrm{CE}$ & $5 \mathrm{RS}$ \\
\hline 1 & ADS & 53 & 6 & 60 & 24 & 0 & 6 & 18 & 24 & 0 & 6 & 18 \\
34 & JMF & 49 & 12 & 29 & 24 & 0 & 23 & 1 & 23 & 0 & 21 & 2 \\
35 & JPF & 55 & 8 & 30 & 21 & 0 & 0 & 21 & 21 & 0 & 0 & 21 \\
60 & SLG & 49 & 5 & 20 & 24 & 8 & 16 & 0 & 24 & 2 & 21 & 1 \\
61 & SFA & 67 & 25 & 15 & 18 & 1 & 1 & 16 & 18 & 1 & 1 & 16 \\
\hline
\end{tabular}

Anexo 7

PACIENTES DO SEXO MASCULINO COM MEGARRETO

\begin{tabular}{ccccccccccccc}
\hline ID & PACIENTE & IDADE & DIS & DIAS & $3 D$ & $3 C D$ & $3 C E$ & $3 R S$ & $5 D$ & $5 C D$ & $5 C E$ & $5 R S$ \\
\hline 2 & AAN & 65 & 10 & 15 & 22 & 0 & 2 & 20 & 21 & 0 & 3 & 18 \\
3 & AFP & 63 & 1 & 8 & 21 & 13 & 3 & 5 & 21 & 13 & 3 & 5 \\
6 & ARS & 43 & 5 & 15 & 22 & 2 & 9 & 11 & 20 & 0 & 4 & 16 \\
7 & AGM & 61 & 10 & 15 & 24 & 3 & 13 & 8 & 24 & 1 & 9 & 14 \\
9 & ARS & 67 & 2 & 15 & 24 & 1 & 0 & 23 & 23 & 3 & 0 & 20 \\
13 & AFB & 52 & 5 & 20 & 21 & 0 & 8 & 13 & 21 & 0 & 5 & 16 \\
19 & ECB & 32 & 1 & 30 & 19 & 8 & 8 & 3 & 19 & 8 & 8 & 3 \\
20 & EFS & 62 & 1 & 8 & 24 & 3 & 5 & 16 & 24 & 4 & 9 & 11 \\
23 & FFB & 61 & 3 & 10 & 23 & 0 & 6 & 17 & 23 & 0 & 8 & 15 \\
30 & JSR & 67 & 1 & 8 & 24 & 9 & 7 & 8 & 22 & 0 & 8 & 14 \\
31 & JVS & 62 & 4 & 15 & 20 & 17 & 3 & 0 & 22 & 6 & 7 & 9 \\
32 & JE & 60 & 33 & 15 & 21 & 0 & 0 & 21 & 21 & 0 & 0 & 21 \\
33 & JJR & 64 & 15 & 10 & 24 & 0 & 3 & 21 & 24 & 0 & 0 & 24 \\
36 & JRG & 64 & 1 & 8 & 24 & 22 & 2 & 0 & 23 & 22 & 1 & 0 \\
37 & JZM & 72 & 10 & 25 & 24 & 0 & 0 & 24 & 24 & 1 & 0 & 23 \\
39 & JGC & 69 & 20 & 90 & 23 & 2 & 13 & 8 & 22 & 1 & 8 & 13 \\
42 & LGM & 67 & 30 & 10 & 24 & 0 & 3 & 21 & 24 & 0 & 4 & 20 \\
43 & MB & 51 & 10 & 34 & 18 & 0 & 18 & 0 & 18 & 0 & 18 & 0 \\
57 & OAO & 52 & 15 & 15 & 24 & 2 & 16 & 6 & 24 & 0 & 15 & 9 \\
58 & RJA & 47 & 1 & 8 & 24 & 0 & 16 & 8 & 24 & 0 & 10 & 14 \\
59 & SFS & 47 & 5 & 30 & 18 & 0 & 9 & 9 & 18 & 0 & 9 & 9 \\
62 & VPM & 62 & 10 & 30 & 22 & 1 & 7 & 14 & 11 & 0 & 4 & 7 \\
64 & VFO & 62 & 10 & 15 & 24 & 2 & 2 & 20 & 24 & 0 & 6 & 18 \\
\hline
\end{tabular}




\section{Anexo 8}

\section{PACIENTES DO GRUPO CONTROLE}

\begin{tabular}{|c|c|c|c|c|c|c|c|c|c|c|c|}
\hline ID & PACIENTE & IDADE & SEXO & $3 \mathrm{D}$ & $3 C D$ & $3 \mathrm{CE}$ & $3 \mathrm{RS}$ & $5 \mathrm{D}$ & $5 \mathrm{CD}$ & $5 \mathrm{CE}$ & $5 \mathrm{RS}$ \\
\hline 1 & AGG & 32 & $\mathrm{~F}$ & 20 & 0 & 6 & 14 & 5 & 0 & 0 & 5 \\
\hline 2 & AM & 43 & $\mathrm{~F}$ & 0 & 0 & 0 & 0 & 0 & 0 & 0 & 0 \\
\hline 3 & EPO & 24 & $\mathrm{~F}$ & 0 & 0 & 0 & 0 & 0 & 0 & 0 & 0 \\
\hline 4 & EAO & 35 & $\mathrm{~F}$ & 0 & 0 & 0 & 0 & 0 & 0 & 0 & 0 \\
\hline 5 & FSS & 20 & $\mathrm{~F}$ & 3 & 0 & 0 & 3 & 0 & 0 & 0 & 0 \\
\hline 6 & IMS & 40 & $\mathrm{~F}$ & 2 & 0 & 0 & 2 & 0 & 0 & 0 & 0 \\
\hline 7 & KPS & 23 & $\mathrm{~F}$ & 0 & 0 & 0 & 0 & 0 & 0 & 0 & 0 \\
\hline 8 & LFS & 35 & $\mathrm{~F}$ & 0 & 0 & 0 & 0 & 0 & 0 & 0 & 0 \\
\hline 9 & MCT & 42 & $\mathrm{~F}$ & 1 & 0 & 1 & 0 & 0 & 0 & 0 & 0 \\
\hline 10 & MLS & 38 & $\mathrm{~F}$ & 0 & 0 & 0 & 0 & 0 & 0 & 0 & 0 \\
\hline 1 & CPS & 28 & M & 1 & 0 & 0 & 1 & 0 & 0 & 0 & 0 \\
\hline 12 & $\mathrm{CR}$ & 30 & M & 14 & 1 & 7 & 6 & 0 & 0 & 0 & 0 \\
\hline 13 & ECO & 35 & M & 0 & 0 & 0 & 0 & 0 & 0 & 0 & 0 \\
\hline 14 & $\mathrm{FG}$ & 22 & M & 0 & 0 & 0 & 0 & 0 & 0 & 0 & 0 \\
\hline 15 & IA & 21 & M & 0 & 0 & 0 & 0 & 0 & 0 & 0 & 0 \\
\hline 16 & JFS & 25 & M & 0 & 0 & 0 & 0 & 0 & 0 & 0 & 0 \\
\hline 17 & JÁ & 29 & $M$ & 0 & 0 & 0 & 0 & 0 & 0 & 0 & 0 \\
\hline 18 & $\mathrm{JP}$ & 35 & $M$ & 0 & 0 & 0 & 0 & 0 & 0 & 0 & 0 \\
\hline 19 & LH & 25 & $M$ & 0 & 0 & 0 & 0 & 0 & 0 & 0 & 0 \\
\hline 20 & SGN & 35 & $\mathrm{M}$ & 0 & 0 & 0 & 0 & 0 & 0 & 0 & 0 \\
\hline
\end{tabular}




\section{REFERÊNCIAS BIBLIOGRÁFICAS}




\subsection{Referências Bibliográficas}

AMORIM, M.; CORREIA NETO, A. Histopathologia e pathogenese do megaesophago e megarecto. (Considerações em torno de um caso de "mal de engasgo"). Anais Fac. Med. São Paulo, v.8, p.101-127, 1932.

ALCÂNTARA, F.G.; OLIVEIRA, J.A.M. Estudo quantitativo dos neurônios do plexo de Auerbach e sua distribuição no tubo digestivo do rato wistar. Rev. Bras. Med., v.21, p.369-371, 1964.

ALMEIDA, A.C. Resultados funcionais da operação de Duhamel-Haddad no tratamento do megacolo chagásico. Goiânia, 1996. 74p. Dissertação (Mestrado) - Instituto de Patologia Tropical e Saúde Pública, Universidade Federal de Goiás.

ARHAN, P.; DEVROEDE, G.; JEHANNIN, B.; LANZA, M.; FAVERDIN, C.; DORNIC, C.; PERSOZ, B.; TÉTREAULT, L.; PEREY, B.; PELERIN, D. Segmental colonic transit time. Dis. Colon Rectum, v.24, p.625-9, 1981.

BARRETO, M.P. Epidemiologia. In: BRENER, Z.; ANDRADE, Z. Trypanosoma cruzi e doença de Chagas. Rio de Janeiro, GuanabaraKoogan, 1979. p.89-151.

BECKER, V.; ELSBORG, L. A new method for the determination of gastrointestinal transit times. Scand. J. Gastroenterol., v.14, p.355-359, 1979.

BENMAIR, Y.; FISCHEL, B.; FREI, E.H.; GILAT, T. Evaluation of a magnetic method for the measurement of small intestinal transit time. Am. J. Gastroenterol., v.68, p.470-475, 1977.

BOND Jr, J.H.; LEVITT, M.D. Investigation of small bowel transit time in man utilizing pulmonary hydrogen (H2) measurements. J. Lab. Clin. Med., v.85, p.546-555, 1975.

BOUCHOUCHA, M.; DEVROEDE, G.; ARHAN, P.; STROM, B.; WEBER, J.; CUGNENC, P.H.; DENIS, P.; BARBIER, J.P. What is the meaning of the colorectal transit time measurement? Dis. Colon Rectum, v.35, p.773-782, 1992.

CHAGAS, C. Nova tripanossomíase humana estudos sobre a morfologia e o ciclo evolutivo do Schyzotrypanum cruzi n.gen., n.sp., agente etiológico de nova entidade mórbida do homem. Mem. Inst. Oswaldo Cruz, v.1, p.159-218, 1909. 
CHAGAS, C. Nova entidade mórbida do homem, resumo geral dos estudos etiológicos e clínicos. Mem. Inst. Oswaldo Cruz, v.3, p.219-275, 1911.

CHAUSSADE, S.; ROCHE, H.; KHYARI, A.; COUTURIER, D.; GUERRE, J. Measure du temps de transit colique (TTC): description et validation d'une nouvelle tecnique. Gastroenterol. Clin. Biol., v.10, p.385-389, 1986.

CIPRIANO-GAMA, R.; COSTA, J.H.G.; AZEVEDO, I.F. Tratamento cirúrgico do megacólon chagásico pela técnica de Duhamel-Haddad experiência no Hospital Geral de Goiânia: análise de 204 casos. Rev. Bras. Coloproctol., v.6, p.84-88, 1986.

CUTAIT, D.E.; FIGLIOLINI, F.J.; BRANCO, P.D.; ALTENFELDER, P.; SPERANZINI, M.; CAMPOS, S.M.; FERREIRA, E.A.B.; BIROLINI, D.; FUJIMURA, I.; OLIVEIRA, M.R.; BASTOS, E.S. Experiência com o tratamento do megacólon adquirido pela retossigmoidectomia e descrição da técnica da anastomose colo-retal retardada. Rev. Assoc. Méd. Bras., v.11, p.429-435, 1965.

CORRÊA NETTO, A. Tratamento cirúrgico do megacólon pela ressecção dos chamados esfíncteres funcionais do intestino grosso. Rev. Cir. São Paulo, v.1, p.249-243, 1934.

CUTAIT, D.E.; CUTAIT, R. Surgery of chagasic megacolon. World J. Surg., V.15, p.188-197, 1991.

DEVROEDE, G. Constipation. In: SLEISENGER, M.H.; FORDTRAN, J.S. Gastrointestinal disease. 2. ed. Philadelphia, W.B. Saunders Company, 1993. p.837-887.

DIAS, J.C.P. História natural da doença de Chagas. Rev. Patol. Trop., v.29, p.47-66, 2000.

ETZEL, E. Neuropathologia do megaesôfago e megacólon. Anais Fac. Med. São Paulo, v.10, p.382-395, 1934.

FERREIRA SANTOS, E. Megacolon and megarectum in Chagas disease. Proc. R. Soc. Med., v.54, p.1049-1053, 1961.

HABR-GAMA, A. Motilidade do cólon sigmóide e do reto: contribuição à fisiologia do megacólon chagásico. São Paulo, 1966. 87p. Tese (Inaugural) - Faculdade de Medicina, Universidade de São Paulo.

HABR-GAMA, A.; SIMONSEN, O.; HADDAD, J.; RAIA, A.A.; CORRÊA NETTO, A. Volvo do sigmóide - Considerações gerais e resultados do tratamento conservador pelo esvaziamento endoscópico. Rev. Assoc. Méd. Bras., v.14, p.287-292, 1968. 
HABR-GAMA, A.; COSTA-CURTA, L.; RAIA, A.A. Anatomia e fisiologia do esfíncter interno do ânus. Rev. Bras. Colo-Proctol., v.3, p.21-30, 1970.

HABR-GAMA, A.; HADDAD, J.; MONTENEGRO, E.S.; SIMONSEN, O.; RAIA, A.A. Volvo do sigmóide, etiologia, fisiopatologia e tratamentoConsiderações sobre 190 casos. Rev. Hosp. Clín. Fac. São Paulo, v.28, p.112-120,1973.

HABR-GAMA, A.; HABERKORN, S.; GAMA-RODRIGUES, J.J.; RAIA, A.A.; BETTARELLO, A. Manometria ano-reto-cólica comportamento motor normal e patológico. Arq. Gastroenterol. (São Paulo), v.11, p.201-216, 1974.

HABR-GAMA, A.; HADDAD, J.; SIMONSEN, O.; WARDE, P.; MANZIONE, A.; SILVA. J.H.; IOSHIMOTO, M.; CUTAIT, D.; RAIA, A.A. Volvulus of the sigmoid colon in Brazil: a report of 230 cases. Dis. Colon Rectum, v.19, p.314-320, 1976.

HABR-GAMA, A.; GOFFI, F.S.; RAIA, A.A.; FERRÃO, S.O.T.; YAMAGUSHI, N. Tratamento cirúrgico do megacólo: Operação de Duhamel-Haddad. Rev. Col. Bras. Cir., v.9, p.25-31, 1982.

HABR-GAMA, A.; SOUZA JR,. A.H.S.; SILVA, J.H.; ALVES, P.R.A.; VIEIRA, M.J.F.; PINOTTI, H.W. Modificação técnica no abaixamento do cólon com anastomose coloanal. Rev. Bras. Colo-Proctol., v.9, p.15, 1989. Suplemento 1.

HABR-GAMA, A.; KISS, D.R.; BOCHINI, S.F.; TEIXEIRA, M.G.; PINOTTI, H.W. Megacólon chagásico - tratamento pela retossigmoidectomia abdominal com anastomose mecânica colorretal término-lateral: resultados preliminares. Rev. Hosp. Clín. Fac. Med. São Paulo, v.49, p.199-203, 1994.

HERNANDEZ, E.B.R. Estudo clínico e radiológico do reto-sigmóide em indivíduos de uma área endêmica de doença de Chagas, Mambaí (GO). Brasília, 2002. 112p. Tese (Doutorado) - Faculdade de Medicina, Universidade de Brasília.

HINTON, J.M.; LENNARD-JONES, J.E.; YOUNG, A.C. A new method for studying gut transit time using radiopaque markers. Gut, v.10, p.842-847, 1969.

JORGE, J.M.N.; HABR-GAMA, A. Tempo de trânsito colônico total e segmentar: análise crítica dos métodos e estudo em indivíduos normais com marcadores radiopacos. Rev. Bras. Colo-Proctol., v.11, p.55-60, 1991.

JORGE, J.M.N.; WEXNER, S.D. Anorectal manometry: techniques and clinical applications. South Med. J., v.86, p.924-930, 1993. 
JORGE, J.M.N.; HABR-GAMA, A.; WEXNER, S.D.; EHRENPREIS, E.D. Teste do hidrogênio expirado com lactulose como medida do tempo de trânsito orocecal (TTOC) em indivíduos normais e constipados. Rev. Bras. Colo-Proctol., v.13, p.84-90, 1993.

KEIGHLEY, M.R.B. Constipação. In: KEIGHLEY, M.R.B.; WILLIAMS, N.S. Cirurgia do ânus, reto e colo. São Paulo, Editora Manole, 1998. p.585-612.

KISS, D.R. Contribuição para o estudo da ultraestrutura da célula muscular lisa no megacólon adquirido. São Paulo, 1970. 75p. Tese (Doutorado) - Universidade de São Paulo.

KISS, D.R.; HABR-GAMA, A; PINOTTI, H.W. Megacólon chagásico: considerações sobre novas perspectivas fisiopatológicas Rev. Paul. Med., v.104, p.145-155, 1986.

KISS, D.R. Megacólon chagásico. In: PINOTTI, H.W. Tratado de clínica cirúrgica do aparelho digestivo. São Paulo, Atheneu, 1994. p.1227-1235.

KÖEBERLE, F. Patogênese dos megas. Rev. Goiana Med., v.2, p.101-110, 1956.

KÖEBERLE, F. Patogenia da moléstia de Chagas, estudo dos órgãos musculares ocos. Rev. Goiana Med., v.3, p.155-180, 1957.

KÖEBERLE, F. Enteromegaly and cardiomegaly in Chagas' disease. Gut, v.4, p.399-405, 1963.

ÖEBERLE, F.; ALCÂNTARA, F.G. Mecanismo de destruição neuronal do sistema nervoso periférico na moléstia de Chagas. O Hospital, v.57, p.1057-1062, 1960.

KREVSKY, B.; MALMUD, L.S.; D'ERCOLE, F.; MAURER, A.H.; FISHER, R.S. Colonic transit scintigraphy. Gastroenterology, v.91, p.1102-1112, 1986.

KUIJPERS, H.C. Defecography. Semin. Colon Rectal Surg., v.3, p.75-78, 1992.

LINS NETO, M.A.F. Operação de Duhamel modificada com anastomose colorretal imediata para o tratamento do megacólon chagásico: técnica e resultados. São Paulo, 1997. 87p. Dissertação (Mestrado) Faculdade de Medicina, Universidade de São Paulo.

LUQUETTI, A.O. Diagnóstico etiológico da doença de Chagas. Rev. Patol. Trop., v.29, p.145-149, 2000. Suplemento 1. 
MAGALHÃES, F.F. Tempo de trânsito colônico. In: CASTRO, L.P.; SAVASSI-ROCHA, P.R.; LIMA, D.C.A.; TANURE, J.C. Tópicos em gastroenterologia vol. 8. Rio de Janeiro, Medsi, 1998. p.341-347.

MARSDEN, P.D. The control of Latin American trypanossomiasis. Rev. Soc. Bras. Med. Trop., v.30, p.521-527, 1997.

MARTELLI, H.; DEVROEDE, G.; ARHAN, P.; DUGUAY, C.; DORNIC, C.; FAVERDIN, C. Some parameters of large bowel motility in normal man. Gastroenterology, v.75, p.612-618, 1978.

METCALF, A.M.; PHILLIPS, S.F.; ZINSMEISTER, A.R.; MACCARTY, R.L.; BEART, R.W.; WOLFF, B.G. Simplified assessment of segmental colonic transit time. Gastroenterology, v.92, p.40-47, 1987.

MOREIRA, $\mathrm{H}$. Estudo eletromanométrico da atividade motora do coto retal e do colo descendente em pacientes chagásicos submetidos às operações de Hartmann e de Duhamel. Goiânia, 1970. 133p. Tese (Doutorado) - Faculdade de Medicina, da Universidade Federal Goiás.

MOREIRA, $\mathrm{H}$. Estudo eletromanométrico da atividade motora do coto retal e do colo descendente em pacientes chagásicos submetidos às operações de Hartmann e de Duhamel. Rev. Goiana Med., v.20, p.125-170, 1974.

MOREIRA, H. Megacólon chagásico. In: A gastroenterolgia no Brasil. Rio de Janeiro, Revinter, 2000. p.377-407.

NAHAS, S.C. Tratamento cirúrgico do megacólon chagásico pela retossigmoidectomia abdominal com anastomose mecânica colorretal término-lateral posterior imediata. São Paulo, 2000. 112p. Tese (Livre Docência) - Faculdade de Medicina, Universidade de São Paulo.

OKUMURA, M.; CORRÊA NETTO, A. Produção experimental de megas em animais inoculados com Trypanosoma cruzi. Rev. Hosp. Clín. (São Paulo), v.16, p.338-341, 1961.

PRESTON, D.M.; LENNARD-JONES, J.E.; THOMAS, B.M. Towards a radiologic definition of idiopathic megacolon. Gastrointest. Radiol., v.10, p.167-169, 1985.

PRESTON, D.M.; LENNARD-JONES, J.E. Severe chronic constipation of yong women. Idiopathic slow transit constipation. Gut., v.27, p.41-48. 1986.

RAIA, A.A.; CAMPOS, O.M. Megacólon, contribuição ao estudo de sua patogenia e tratamento. Rev. Med. Cir. São Paulo, v.15, p.431-442, p.467-512, p.519-560, 1955. 
RASSI, A.; REZENDE, J.M.; MOREIRA, H.; XIMENES, C.A.; LUQUETTI, A.O.; LOUSA, L.R.; FERRIOLLI FILHO, F. Associação de cardiopatia, megaesôfago e megacolo na fase crônica da doença de Chagas. Rev. Soc. Bras. Med. Trop., v.19, p.29, 1986. suplemento 2.

REZENDE, J.M. Forma digestiva da moléstia de Chagas. Rev. Goiana Med., v.5, p.193-227, 1959.

REZENDE, J.M.; LUQUETTI, A.O. Chagasic megavisceras. In: PAHO. Chagas' disease and the nervous system. Washington, PAHO, 1994. p.160-183.

SANTOS, S.L.; BARCELOS, I.K.; MESQUITA, M.A. Total and segmental colonic transit time in constipated patients with Chagas disease without megaesophagus or megacolon. Braz. J. Med. Biol. Res., v.33, p.43-49, 2000.

SCHMUNIS, G.A. La tripanosomiasis americana como problema de salud pública. In: Chagas' disease and the nervous system. Washington, PAHO, 1994. p.3-31

SCOTT, A.M.; KNOWLES, C.H.; NEWELL, M.; GARVIE, N.; WILLIAMS, N.S.; LUNNISS, P.J. Scintigraphic assessment of colonic transit in women with slow-transit constipation arising de novo and following pelvic surgery or childbirth. Br. J. Surg., v.88, p.405-411, 2001.

SHERLOCK, I.A. Vectores. In: BRENER, Z.; ANDRADE, Z.A. Trypanosoma cruzi doença de Chagas. Rio de Janeiro, Guanabara Koogan, 1979. p.42-88.

SPILLER, R. Rome II: the functional gastrointestinal disorders, diagnosis pathophysiology and treatment: a multinational consensus. Gut, v.46, p.741, 2000.

THOMPSON, W.G.; LONGSTRETH, G.F.; DROSSMAN D.A.; HEATON, K.W.; IRVINE, E.F.; MULLER-LISSNER, S.A. Functional bowel disorders of the biliary tract and pancreas. Gut, v.45, p. 43-47, 1999. Supplement II.

VASCONCELOS, E.; BOTELHO, G. Cirurgia do megaesôfago. Cia Ed. Nacional. São Paulo, 1937.

VERDURON, A,; DEVROEDE, G,; BOUCHOUCHA, M.; ARHAN, P; SCHANG, J.C.; POISSON, J.; HEMOND, M.; HEBERT, M. Megarectum. Dig. Dis. Sci.,v.33, p.1164-1174, 1988.

VIEIRA, C.B.; GODOY, R.A.; CARRIL, C.F. Hypersensitivity of the large intestine to cholinergi agents in patients with Chagas' disease and megacolon. Rev. Bras. Gastroenterol., v.16, p.41-48, 1964. 
VIEIRA, C.B.; GODOY, R.A.; CARRIL, C.F. Resposta do cólon sigmóide não ectásico à metacolina na forma crônica da moléstia de Chagas. Arq. Gastroenterol., v.3, p.21-26, 1966.

- De acordo com:

UNIVERSIDADE DE SÃO PAULO. Faculdade de Medicina. Serviço de Biblioteca e Documentação. Estrutura e apresentação de dissertação e teses. Elaborado por Anneliese Carneiro da Cunha. São Paulo, Serviço de Biblioteca e documentação, 1996. 